\title{
Kidins220/ARMS controls astrocyte calcium signaling and neuron-astrocyte communication
}

\author{
Fanny Jaudon ${ }^{1}{ }^{1}$ Martina Chiacchiaretta ${ }^{1,6} \cdot$ Martina Albini ${ }^{1,2} \cdot$ Stefano Ferroni ${ }^{3} \cdot$ Fabio Benfenati $\mathbb{C}^{1,4}$. \\ Fabrizia Cesca $\mathbb{D}^{1,5}$
}

Received: 21 December 2018 / Revised: 30 September 2019 / Accepted: 30 September 2019 / Published online: 17 October 2019

(c) The Author(s), under exclusive licence to ADMC Associazione Differenziamento e Morte Cellulare 2019

\begin{abstract}
Through their ability to modulate synaptic transmission, glial cells are key regulators of neuronal circuit formation and activity. Kidins220/ARMS (kinase-D interacting substrate of $220 \mathrm{kDa} /$ ankyrin repeat-rich membrane spanning) is one of the key effectors of the neurotrophin pathways in neurons where it is required for differentiation, survival, and plasticity. However, its role in glial cells remains largely unknown. Here, we show that ablation of Kidins 220 in primary cultured astrocytes induced defects in calcium $\left(\mathrm{Ca}^{2+}\right)$ signaling that were linked to altered store-operated $\mathrm{Ca}^{2+}$ entry and strong overexpression of the transient receptor potential channel TRPV4. Moreover, Kidins $220^{-1-}$ astrocytes were more sensitive to genotoxic stress. We also show that Kidins220 expression in astrocytes is required for the establishment of proper connectivity of cocultured wild-type neurons. Altogether, our data reveal a previously unidentified role for astrocyteexpressed Kidins 220 in the control of glial $\mathrm{Ca}^{2+}$ dynamics, survival/death pathways and astrocyte-neuron communication.
\end{abstract}

\section{Introduction}

Astrocytes are the most abundant glial cell type in the central nervous system and play crucial roles in regulating brain function and homeostasis, being involved in various processes such as neurotransmitter clearance, neuronal migration, synapse formation, and synaptic plasticity [1, 2]. They

Edited by L. Greene

Supplementary information The online version of this article (https:// doi.org/10.1038/s41418-019-0431-5) contains supplementary material, which is available to authorized users.

Fabrizia Cesca

fcesca@units.it

1 Center for Synaptic Neuroscience and Technology, Istituto Italiano di Tecnologia, 16132 Genova, Italy

2 Department of Experimental Medicine, University of Genova, 16132 Genova, Italy

3 Department of Pharmacy and Biotechnology, University of Bologna, 40126 Bologna, Italy

4 IRCCS Ospedale Policlinico San Martino, Genova, Italy

5 Department of Life Sciences, University of Trieste, 34127 Trieste, Italy

6 Present address: Department of Neuroscience, Tufts University School of Medicine, Boston, MA, USA express a wide variety of channels and neurotransmitter receptors and are able to release numerous factors that allow them to maintain a continuous bidirectional communication with neurons [2-4]. Astrocytes are not electrically active and elevation of intracellular calcium concentration $\left(\left[\mathrm{Ca}^{2+}\right]_{\mathrm{i}}\right)$ is one of the key regulators of signaling to neurons [5, 6]. Specifically, increase of $\left[\mathrm{Ca}^{2+}\right]_{i}$ drives the release of several gliotransmitters in vitro and in situ, including glutamate and ATP, which can act in autocrine fashion on the same astrocytes, and/or induce paracrine effects on neighboring neurons $[2,7]$. Fine-tuning of astrocytic $\left[\mathrm{Ca}^{2+}\right]_{\mathrm{i}}$ is therefore essential for modulating neuronal circuits and connectivity.

Besides shaping the connectivity and functionality of neighboring neurons, astroglia $\left[\mathrm{Ca}^{2+}\right]_{\mathrm{i}}$ dynamics have been recently shown to play an important role in the physiological processes leading to cognition and memory formation [8], by coordinating and priming the activity of specific neural circuits $[9,10]$. Not surprisingly, dysfunctions in astroglia $\left[\mathrm{Ca}^{2+}\right]_{\mathrm{i}}$ signaling have been shown to play a causal role in the neurodegenerative processes common to a number of pathogenic conditions, such as those described in aging and in Alzheimer's disease [11], as well as in behavioral alterations and disorders of cognition [12-14]. Because astroglial dysfunctions appear to be a common hallmark of several neurologic disorders, astrocytes are also endowed with increasing clinical relevance, as they may 
represent an alternative and easier target for drugs than neurons [15]. In this view, any further contribution to the understanding of the cellular substrates of glial $\left[\mathrm{Ca}^{2+}\right]_{\mathrm{i}}$ signaling is of potential interest for biomedical applications.

Kidins220 (Kinase-D interacting substrate of $220 \mathrm{kDa}$ ), also known as ARMS (Ankyrin repeat-rich membrane spanning) is a transmembrane protein preferentially expressed in the nervous system [16, 17]. It mediates the intracellular signaling cascades initiated by Trk and p75 neurotrophin $\left(\mathrm{p} 75^{\mathrm{NTR}}\right)$ receptors upon neurotrophin binding [18]. Kidins220 also interacts with other membrane receptors, like vascular endothelial growth factor-, glutamate-, and ephrin receptors [19-22], and it is thus a common converging target of several trophic stimuli. Kidins 220 has been extensively studied in neurons, where it is required for differentiation, survival, and synaptic plasticity [23, 24]. Studies in Kidins 220 mutant mice revealed that the complete ablation of Kidins 220 leads to embryonic death associated with apoptosis in the central and peripheral nervous systems and cardiovascular abnormalities [22, 25]. Studies in adult mice showed that a partial reduction of Kidins 220 levels is sufficient to induce synaptic deficits and affect higher cognitive functions such as learning and memory [26-29]. While the role of Kidins220 in neurons has been comprehensively addressed through in vitro and in vivo studies, its function in astroglial cells is still completely unexplored. In this study, we investigated the role of Kidins 220 in astrocytes using primary cultures derived from Kidins $220^{-1-}$ and wild-type embryo littermates, and postnatal cultured astrocytes derived from Kidins $220^{\text {lox/lox }}$ mice in which Kidins 220 depletion was acutely induced by lentivirus-expressed Cre recombinase. Our data show that besides its well-established role in neurons, Kidins 220 plays an important role in astrocytes modulating intracellular $\mathrm{Ca}^{2+}$ dynamics, survival and death pathways as well as astrocyte-neuron communication.

\section{Materials and methods}

\section{Animals}

All embryos used in this study were obtained from crosses of Kidins $220^{+/-}$mice $[22,30]$ in the C57BL/6 background. Mice were mated overnight and separated in the morning. The development of the embryos was timed from the detection of a vaginal plug, which was considered day 0.5. Postnatal cultures were prepared from P0-P1 pups obtained from crosses of Kidins $220^{+/ l o x}$ mice on the C57BL/6 background. All experiments were carried out in accordance with the guidelines established by the European Community Council (Directive 2010/63/EU of September 22, 2010) and were approved by the Italian Ministry of Health.

\section{Antibodies}

The following primary antibodies were used: rabbit polyclonal anti-Kidins220 (GSC16, \#AB34790, Abcam, Cambridge, UK), rabbit monoclonal anti-GAPDH (14C10, \#2118, Cell signaling, Leiden, The Netherlands), rabbit polyclonal anti-active caspase 3 (\#AF835, R\&D Systems, Minneapolis, MN, USA), rabbit anti- $\beta$ tubulin III (\#T2200, Sigma-Aldrich, Milan, Italy), guinea pig polyclonal anti-vesicular glutamate transporter-1 (VGLUT1, \#AB5905, Merck-Millipore, Darmstadt, Germany), rabbit polyclonal anti-vesicular GABA transporter (VGAT, \#131003, Synaptic System, Goettingen, Germany), mouse monoclonal anti-glial fibrillary acidic protein (GFAP, \#G3893, Sigma-Aldrich), rabbit polyclonal anti-TRPV4 (\#ab39260, Abcam), mouse anti-neuronal nuclei (NeuN, \#MAB377, Merck-Millipore), chicken antiNeuN (\#266006, Synaptic Systems), guinea pig anti-Iba1 (\#234004, Synaptic Systems), and rabbit anti-Olig2 (\#AB9610, Merck-Millipore).

Secondary antibodies for western blot analysis were ECL Plex goat anti-rabbit IgG-Cy5 (PA45012, GE Healthcare, Milan, Italy), ECL Plex goat anti-mouse IgG-Cy3 (PA43009, GE Healthcare), HRP-conjugated goat antirabbit antibodies (\#31460, Thermo Fisher Scientific, Waltham, MA, USA), and HRP-conjugated goat anti-mouse antibodies (\#31430, Thermo Fisher Scientific). Fluorescently conjugated secondary antibodies for immunocytochemistry were from molecular probes (Thermo Fisher Scientific; Alexa Fluor 488, \#A11029; Alexa Fluor 647, \#A21450 and \#A32933; Alexa Fluor 568, \#A11031 and A11011; Alexa Fluor 405, \#A31556). Hoechst (\#B2261, Sigma-Aldrich) was used to stain nuclei.

\section{Primary astrocyte culture}

E18.5 or P0-P1 cortices were dissected in ice-cold phosphate buffered saline (PBS), incubated with trypsin $0.25 \%$ and $1 \mathrm{mg} / \mathrm{ml}$ DNase I for $30 \mathrm{~min}$ at $37^{\circ} \mathrm{C}$, and mechanically dissociated. Cells were then resuspended and plated on poly-D-lysine-coated flasks or glass coverslips, in MEM medium containing 10\% FBS, 2 mM glutamine, 33 $\mathrm{mM}$ glucose and antibiotics (astrocyte culture medium). After $24 \mathrm{~h}$, the medium was removed and replaced with fresh culture medium. After 1 week, half of the medium was replaced with fresh culture medium. The purity of the culture was verified by immunostaining using anti-GFAP, anti-NeuN/anti- $\beta$-tubulin III, anti-Olig2 and anti-Iba1 antibodies to identify astrocytes, neurons, oligodendrocytes, and microglia, respectively (Fig. S1). This showed that embryonic and postnatal cultures were composed of about $88 \%$ astrocytes and were totally devoid of neurons. 


\section{Lentivirus production and infection procedures}

HEK293T (ATCC CRL-3216) cells were maintained in Iscove's Modified Dulbecco's Medium supplemented with $10 \%$ FBS, $2 \mathrm{mM}$ Glutamine, $100 \mathrm{U} / \mathrm{ml}$ penicillin, and 0.1 $\mathrm{mg} / \mathrm{ml}$ streptomycin in a $5 \% \mathrm{CO}_{2}$ humidified incubator at $37^{\circ} \mathrm{C}$. Cells were routinely tested for mycoplasma, and resulted mycoplasma free. Cells were transfected with the $\Delta 8.9$ encapsidation plasmid, the VSVG envelope plasmid and the pLenti-PGK-Cre-EGFP or pLenti-PGK- $\Delta$ CreEGFP plasmids [31] using the calcium phosphate method. The transfection medium was replaced by fresh medium after $16 \mathrm{~h}$. Supernatants were collected $36-48 \mathrm{~h}$ after transfection, centrifuged to remove cell debris, passed through a $0.45 \mu \mathrm{m}$ filter, and ultracentrifuged $2 \mathrm{~h}$ at $20,000 \times g$ at $4{ }^{\circ} \mathrm{C}$. Viral pellets were resuspended in PBS, aliquoted and stored at $-80^{\circ} \mathrm{C}$ until use.

Confluent postnatal cultures were trypsinized and seeded on six-well plates or glass coverslips coated with poly-Dlysine for subsequent experiments. Cells were infected 3 days later with lentiviruses encoding catalytically dead $(\Delta \mathrm{Cre})$ or active Cre recombinase with the lowest infectious dose capable of transducing $\geq 95 \%$ of cells (dilution range 1:500-1:800) and used for experiments $\geq 7$ days after transduction.

\section{Astrocyte-neuron cocultures}

Once the astrocytes reached confluence, they were trypsinized and plated at the same relative density on glass coverslips that had been coated with poly-D-lysine; cultures were then maintained for 3 days in astrocyte culture medium. Twentyfour hours before adding neurons, astrocytes cultures were changed to Neurobasal medium containing B27 supplements, glutamax, and antibiotics. Neurons were prepared from E18.5 mice as described previously $[22,30]$ and plated directly onto established astrocyte cultures at 20,000 cells/coverslip. Cells were then fixed in $4 \%$ PFA at $3,5,7$, or 10 DIV and morphological analysis was performed.

\section{Calcium imaging}

Astrocytes at 3 DIV or at 7-8 DIV after lentivirus infection were loaded with $1 \mu \mathrm{g} / \mathrm{ml}$ Fura-2-AM (\#F1221, Thermo Fisher Scientific) in astrocyte culture medium for $30 \mathrm{~min}$ at $37^{\circ} \mathrm{C}$. Subsequently, cells were washed in recording buffer (10 mM HEPES pH 7.4, $150 \mathrm{mM} \mathrm{NaCl}, 3 \mathrm{mM} \mathrm{KCl}, 1 \mathrm{mM}$ $\mathrm{MgCl}_{2}, 10 \mathrm{mM}$ Glucose, and $\left.2 \mathrm{mM} \mathrm{CaCl} 2\right) 30 \mathrm{~min}$ at $37^{\circ} \mathrm{C}$ to allow hydrolysis of the esterified groups. Coverslips with cells were mounted on the imaging chamber and loaded with $0.45 \mathrm{ml}$ of recording buffer. Fura-2-loaded cultures were observed with an inverted Leica 6000 microscope using a HCX PL APO lambda blue $63.0 \times 1.40$ oil- immersion objective. For analyzing ATP-evoked $\left[\mathrm{Ca}^{2+}\right]_{\mathrm{i}}$ transients, $50 \mu \mathrm{l}$ of ATP solution (final concentration 100 $\mu \mathrm{M}$, \#A2383, Sigma-Aldrich) was manually added to the culture medium $15 \mathrm{~s}$ after the beginning of the recordings. Where indicated, cells were preincubated with $10 \mu \mathrm{M}$ U73122 (PLC $\gamma$ inhibitor, \#U6756, Sigma-Aldrich) or U73343 (inactive analog, \#U6881, Sigma-Aldrich) for 10 min before the beginning of the recordings. Samples were excited at 340 and $380 \mathrm{~nm}$ and images of fluorescence emission at $510 \mathrm{~nm}$ were acquired using a HamamatsuC9100-02-LNK00 camera. Calcium levels were estimated from background subtracted ratio images $(340 / 380 \mathrm{~nm})$ of Fura-2-loaded astrocytes at the cell body level according to the equation of Grynkiewicz [32]

$$
\left[\mathrm{Ca}^{2+}\right]=K_{d} \times \frac{R-R_{\min }}{R_{\max }-R} \times \frac{F_{\max }^{380}}{F_{\min }^{380}}
$$

where $R$ is the measured $340 / 380 \mathrm{~nm}$ ratio; $R_{\min }$ and $R_{\max }$ are the ratios in the absence of $\mathrm{Ca}^{2+}$ or when Fura- 2 is saturated by $\mathrm{Ca}^{2+}$, and $F_{\max }^{380}$ and $F_{\min }^{380}$ are the fluorescence intensity of $380 \mathrm{~nm}$ excitation at $0 \mathrm{Ca}^{2+}$ and at $\mathrm{Ca}^{2+}$ saturation. To determine the $K_{d}$ in our system, in situ calibration was performed by using $1 \mu \mathrm{M}$ of the $\mathrm{Ca}^{2+}$-ionophore ionomycin in recording buffer containing an increasing concentration of $\mathrm{Ca}^{2+}$, ranging from 1 to $10 \mathrm{mM}$.

\section{Biochemical techniques}

Cells were washed once in ice-cold PBS and lysed in RIPA buffer $(50 \mathrm{mM}$ Tris- $\mathrm{HCl} \mathrm{pH} 7.4,150 \mathrm{mM} \mathrm{NaCl}, 2 \mathrm{mM}$ EDTA, 1\% NP40, 0.1\% SDS) plus protease and phosphatase inhibitors [complete EDTA-free protease inhibitors, Roche Diagnostic (Monza, Italy); serine/threonine phosphatase inhibitor and tyrosine phosphatase inhibitor, Sigma-Aldrich]. After centrifugation at $16,000 \times g$ for $15 \mathrm{~min}$ at $4{ }^{\circ} \mathrm{C}$, protein concentration was quantified by using the BCA Protein Assay kit (Thermo Fisher Scientific). SDS-PAGE and western blotting were performed by using precast $4-12 \%$ NuPAGE Novex Bis-Tris Gels (Invitrogen, Thermo Fisher Scientific). After incubation with primary antibodies, membranes were incubated with fluorescently conjugated secondary antibodies and revealed by a Typhoon Variable Mode Imager (GE Healthcare) or with HRP-conjugated secondary antibodies and ECL Prime Western Blotting System (\#RPN2106, GE Healthcare) and imaged using a ChemiDoc imaging system (Bio-Rad, Milan, Italy). Immunoreactive bands were quantified by using the ImageJ software.

\section{Immunocytochemistry}

Cells were fixed in PBS/4\% PFA for 15 min, then washed in PBS. Cells were subsequently permeabilized with PBS/ 
$0.2 \%$ Triton-X 100 for $10 \mathrm{~min}$ at room temperature (RT) then incubated with primary antibodies diluted in PBS/1\% BSA overnight at $4{ }^{\circ} \mathrm{C}$ or $2 \mathrm{~h}$ at RT. After washes in PBS, cells were incubated with fluorescent secondary antibodies diluted in PBS/1\% BSA. After washes, coverslips were mounted with Mowiol.

\section{Sholl analysis}

Coverslips with cocultured neurons and astrocytes were fixed at 3 DIV and stained with anti- $\beta$ tubulin III antibodies. Images were acquired with a Leica SP8 confocal microscope with a HCX PL APO lambda blue $40.0 \times 1.40$ OIL UV objective and the Sholl analysis was performed using the Sholl plugin of ImageJ (starting radius $1 \mu \mathrm{m}$, radius step size $5 \mu \mathrm{m}$ ). The total dendritic length was measured with the NeuronJ plugin of ImageJ. At least 20 neurons per condition from five independent wild-type and Kidins $220^{-1-}$ astrocytes cultures were analyzed and averaged.

\section{Stress experiments}

To challenge cells with different kinds of stress, culture medium from coverslips with astrocytes at 14 DIV was removed and kept at $37^{\circ} \mathrm{C}$. Cells were washed twice with HBSS then exposed to 100 or $300 \mu \mathrm{M} \mathrm{H}_{2} \mathrm{O}_{2}$ for $30 \mathrm{~min}$ or exposed to a 25 or $50 \mathrm{~mJ} / \mathrm{cm}^{2}$ UVB radiation with a BioLink Crosslinker BLX-E254. Cells were then washed with HBSS, returned to the culture incubator in their culture medium for $24 \mathrm{~h}$ of recovery at $37^{\circ} \mathrm{C}$ and fixed in PBS/4\% PFA before staining with anti-active caspase 3 antibody to quantify the percentage of apoptotic cells.

\section{Measure of BDNF, glutamine, and ATP concentration in culture supernatants}

To measure BDNF, Glutamine and ATP secretion, culture supernatants were removed from wild-type and Kidins $220^{-1-}$ astrocytes at $15 \mathrm{DIV}$. BDNF protein concentration was measured with the BDNF $\mathrm{E}_{\max }{ }^{\circledR}$ ImmunoAssay System (Promega, Milan, Italy), glutamine concentration was measured with the Glutamine assay kit (Abnova, Taipei City, Taiwan), and ATP concentration was measured with the ATP determination kit (Thermo Fisher Scientific), all according to the manufacturer's instructions.

\section{RNA extraction and RT-qPCR}

Total RNA was extracted with the QIAzol lysis reagent (Qiagen, Milan, Italy) from wild-type and Kidins $220^{-1-}$ astrocyte cultures at 15 DIV. The corresponding cDNAs were prepared by reverse transcription of $1 \mu \mathrm{g}$ of RNA using the SuperScript III First-Strand Synthesis System (Invitrogen,
Thermo Fisher Scientific) with an oligo-dT primer according to the manufacturer's instructions. The resulting cDNAs were used as a template for RT-qPCR using a CFX96 Real-Time PCR Detection System (Bio-Rad) with a SYBR Green master mix (Qiagen). Thermal cycling parameters were $5 \mathrm{~min}$ at $95^{\circ} \mathrm{C}$, followed by 40 cycles of $95^{\circ} \mathrm{C}$ for $15 \mathrm{~s}$, and $60^{\circ} \mathrm{C}$ for $45 \mathrm{~s}$. The relative quantification in gene expression was determined using the $\Delta \Delta \mathrm{Ct}$ method. To normalize expression data, primers for ten commonly used housekeeping genes were used, and the normalization factor was determined using the geNorm software, as described [33]. This led to the selection of the following internal control genes in our assays: transferrin receptor protein 1, TATA-box-binding protein, and Tubulin beta-2A. Sequences of the primers used are listed in Supplementary Table 1.

\section{Electrophysiological recordings}

Wild-type and Kidins $220^{-1-}$ astrocyte cultures were used for patch-clamp recordings. Experiments were performed using an EPC-10 amplifier controlled by PatchMaster software (HEKA Elektronik, Lambrecht/Pfalz, Germany) and an inverted DMI6000 microscope (Leica Microsystems GmbH, Wetzlar, Germany). Patch electrodes fabricated from thick borosilicate glasses were pulled to a final resistance of 4-5 M $\Omega$. Recordings with leak current $>100 \mathrm{pA}$ were discarded. The standard bath saline contained (in $\mathrm{mM}$ ): $140 \mathrm{NaCl}, 4 \mathrm{KCl}, 2 \mathrm{MgCl}_{2}, 2 \mathrm{CaCl}_{2}, 10$ HEPES, 5 glucose, pH 7.4 with $\mathrm{NaOH}$, and adjusted to $315 \mathrm{mOsm} / 1$ with mannitol. The intracellular (pipette) solution was composed of (in mM): $144 \mathrm{KCl}, 2 \mathrm{MgCl}_{2}, 5$ EGTA, 10 HEPES, pH 7.2 with $\mathrm{KOH} ; 300 \mathrm{mOsm} / \mathrm{l}$. Experiments were carried out at RT $\left(20-24{ }^{\circ} \mathrm{C}\right)$. All reagents were purchased from Sigma-Aldrich.

For coculture experiments, primary neurons were recorded by patch-clamp experiments after 14 DIV. Recordings of evoked firing activity in current-clamp configuration were performed in Tyrode's extracellular solution in which D-(-)-2-amino-5-phosphonopentanoic acid (AP5, $50 \mu \mathrm{M})$, 6-cyano-7 nitroquinoxaline-2,3-dione (CNQX, $10 \mu \mathrm{M}$ ), bicuculline methiodide (BIC, $30 \mu \mathrm{M}$ ), and (2 S)-3-[[(1 S)-1(3,4-Dichlorophenyl)ethyl]amino-2-hydroxypropyl](phenylmethyl) phosphinic acid hydrochloride (CGP, $5 \mu \mathrm{M}$ ) were added to block NMDA, non-NMDA, $\mathrm{GABA}_{\mathrm{A}}$, and $\mathrm{GABA}_{\mathrm{B}}$ receptors, respectively. The internal solution was composed of (in mM): $126 \mathrm{~K}$-gluconate, $4 \mathrm{NaCl}, 1 \mathrm{MgSO}_{4}$, $0.02 \mathrm{CaCl}_{2}, 0.1$ BAPTA, 15 glucose, 5 Hepes, 3 ATP, and $0.1 \mathrm{GTP}, \mathrm{pH}$ 7.3. Current-clamp recordings were performed at a holding potential of $-70 \mathrm{mV}$, and action potential (AP) firing was induced by injecting current steps of $10 \mathrm{pA}$ lasting $500 \mathrm{~ms}$. All parameters were analyzed using the Fitmaster (HEKA Elektronik) and GraphPad Prism 6 (GraphPad Software, Inc.) software. 


\section{Statistical analysis}

Data are presented as means \pm S.E.M. throughout the text. The distribution of the data was assessed using the D'Agostino-Pearson omnibus normality test. When comparing two groups unpaired two-sided Student's $t$ test and one-sample $t$-test were used, and equality of variances tested through the $F$ test. When more than two groups were compared, one-way ANOVA or repeated measures ANOVA followed by the Bonferroni's post hoc multiple comparison test, or Kruskal-Wallis followed by the Dunn's multiple comparison test were performed to assess significance as indicated in figure legends, and equality of variances tested through the Brown-Forsythe's and Bartlett's test. Alpha levels for all tests were $0.05 \%(95 \%$ confidence intervals). No statistical methods were used to predetermine sample sizes, however sample sizes in this work (indicated in figure legends) are similar to those previously reported in the literature for similar experiments. The ROUT method with $Q=1 \%$ was used to identify outliers for exclusion from analysis. All statistical procedures were performed using GraphPad Prism 6 software (GraphPad Software, Inc).

\section{Results}

\section{Kidins 220 is required for spontaneous and stimulus- induced calcium signaling in astrocytes}

Spontaneous $\left[\mathrm{Ca}^{2+}\right]_{\mathrm{i}}$ oscillations are essential for communication between astrocytes and neurons $[34,35]$ and partially depend on $\mathrm{IP}_{3} \mathrm{R}$-induced endoplasmic reticulum $\mathrm{Ca}^{2+}$ release [36]. By hydrolyzing phosphatidylinositol-4,5bisphosphate $\left(\mathrm{PIP}_{2}\right)$ to produce inositol-1,4, 5-triphosphate $\left(\mathrm{IP}_{3}\right)$ and diacylglycerol (DAG), PLC $\gamma$ is a major regulator of $\left[\mathrm{Ca}^{2+}\right]_{\mathrm{i}}$ signaling [37]. There is also evidence that $\mathrm{Ca}^{2+}$ permeable ion channels located at the astrocyte plasma membrane are key regulators of $\left[\mathrm{Ca}^{2+}\right]_{\mathrm{i}}$ dynamics [38]. Live imaging with ratiometric Fura-2-AM was used to determine whether Kidins 220 is involved in the generation of spontaneous $\left[\mathrm{Ca}^{2+}\right]_{\mathrm{i}}$ oscillations in astrocytes. Both wild-type and Kidins $220^{-1-}$ embryonic astrocytes displayed spontaneous $\left[\mathrm{Ca}^{2+}\right]_{i}$ oscillations with various dynamics (Fig. 1a). Interestingly, the percentage of cells showing activity was strongly reduced in the absence of Kidins220 (Fig. 1b, left), whereas the amplitude and frequency of $\left[\mathrm{Ca}^{2+}\right]_{\mathrm{i}}$ transients were comparable between Kidins $220^{-1-}$ and wild-type cells (Fig. 1b, middle and right). The reduced number of cells showing spontaneous oscillations could be ascribed to an overall altered maturation of Kidins $220^{-1-}$ embryonic astrocyte cultures. In order to address this point, we took advantage of the conditional allele and prepared primary astrocyte cultures from $\mathrm{P} 0$ to $\mathrm{P} 1$ pups from Kidins $220^{+/ l o x} \times$ Kidins $220^{+/ l o x}$ breeding couples, which allowed us to have both Kidins $220^{+/+}$and Kidins $220^{\text {lox/lox }}$ animals in the same litter. Primary Kidins $220^{\text {lox/lox }}$ cultures were subsequently infected with lentiviruses expressing either the active form of the Cre recombinase to induce Kidins 220 depletion, or a functionally inactive Cre $(\Delta \mathrm{Cre})$ as control ([31], Fig. S2A, B, see "Materials and methods" section for details). We refer to these cultures as "Kidins220-depleted" (Kidins220 $0^{\mathrm{lox} / \mathrm{lox}-\mathrm{Cre}}$ ) and "control" (Kidins220 $20^{\text {lox/lox }-\Delta \mathrm{Cre}}$ ). We first compared spontaneous $\left[\mathrm{Ca}^{2+}\right]_{\mathrm{i}}$ oscillations in embryonic and postnatal wild-type cultures, and observed about $50 \%$ of spontaneously oscillating cells in both cultures (Fig. 1d, left, compared with Fig. 1b, left). The frequency of oscillations was comparable (Fig. 1d, middle, compared with Fig. 1b, middle) but, interestingly, the average amplitude was strongly reduced in postnatal, compared with embryonic, cultures (Fig. 1c compared with Fig. 1a; Fig. 1d, right, compared with Fig. 1b, right). Cre-induced Kidins220 depletion did not affect any of the measured parameters of spontaneous $\left[\mathrm{Ca}^{2+}\right]_{\mathrm{i}}$ transients (Fig. 1c, d). Overall, these data suggest that the chronic deletion of Kidins 220 alters spontaneous $\left[\mathrm{Ca}^{2+}\right]_{\mathrm{i}}$ dynamics in embryonic astrocytes.

We subsequently investigated the role played by Kidins220 in stimulus-induced $\left[\mathrm{Ca}^{2+}\right]_{\mathrm{i}}$ signaling. We therefore monitored the response to ATP stimulation, since ATP is a powerful signaling molecule that modulates $\left[\mathrm{Ca}^{2+}\right]_{\mathrm{i}}$ dynamics in cultured astrocytes [39]. Similarly to what observed for spontaneous oscillations, in embryonic cultures the percentage of cells displaying ATP-evoked $\left[\mathrm{Ca}^{2+}\right]_{\mathrm{i}}$ elevations was strongly reduced in the absence of Kidins 220 (Fig. 1e), confirming the involvement of Kidins 220 in $\left[\mathrm{Ca}^{2+}\right]_{\mathrm{i}}$ signaling. However, the kinetics and the peak amplitudes of the ATP-induced $\left[\mathrm{Ca}^{2+}\right]_{\mathrm{i}}$ rise in cells responding to the ATP challenge were comparable in wild-type and Kidins $220^{-1-}$ astrocytes (Fig. 1f, left, and g). Moreover, the chronic absence of Kidins220 did not affect the dependence of the $\left[\mathrm{Ca}^{2+}\right]_{\mathrm{i}}$ rises upon PLC $\gamma$ activation, as shown by the absence of ATPinduced $\left[\mathrm{Ca}^{2+}\right]_{\mathrm{i}}$ transients in the presence of the specific PLC $\gamma$ inhibitor U73122 (Fig. 1f, right). We next studied the role of Kidins 220 on ATP-induced $\left[\mathrm{Ca}^{2+}\right]_{i}$ transients in postnatal cultures, and found that the responses were comparable to embryonic cultures in terms of percentage of responding cells, kinetics and peak amplitudes, and, importantly, they were not affected by Kidins 220 depletion (Fig. $1 \mathrm{~h}-\mathrm{j}$ ). As for embryonic cultures, ATP-induced $\left[\mathrm{Ca}^{2+}\right]_{\mathrm{i}}$ transients were dependent on PLC $\gamma$, as preincubation with the U73122 PLC $\gamma$ inhibitor completely prevented the response (Fig. 1i, right).

Overall, our data show that Kidins220 affects $\left[\mathrm{Ca}^{2+}\right]_{\mathrm{i}}$ signaling in cultured astrocytes. However, the effects induced by Kidins 220 depletion are observed only in 
A

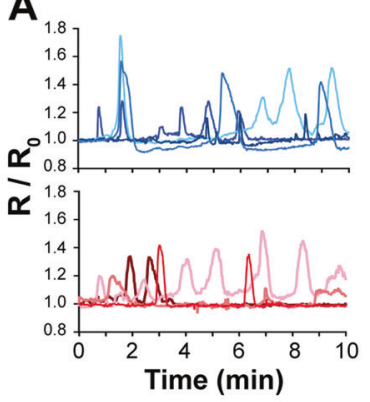

C

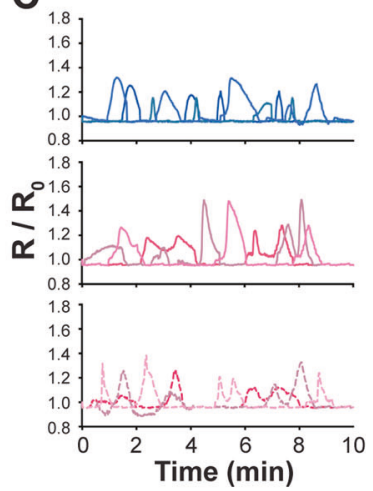

E

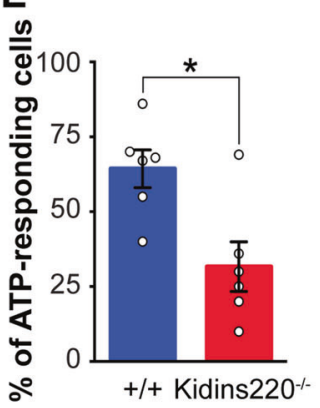

H

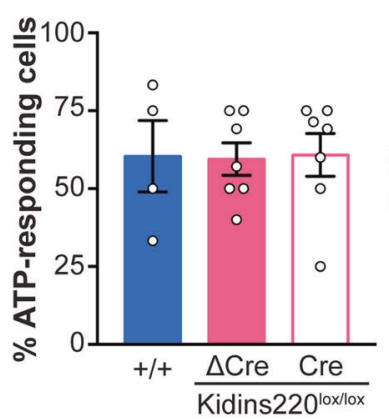

B

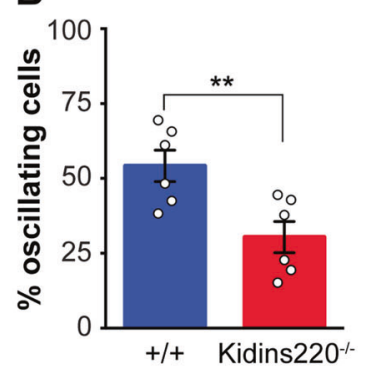

D
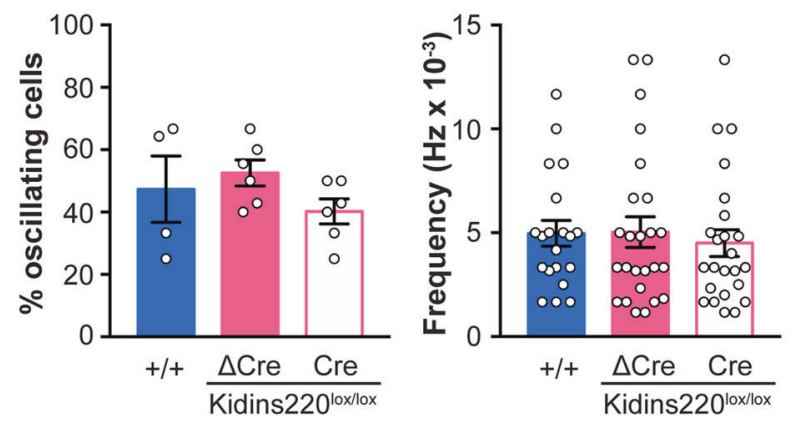
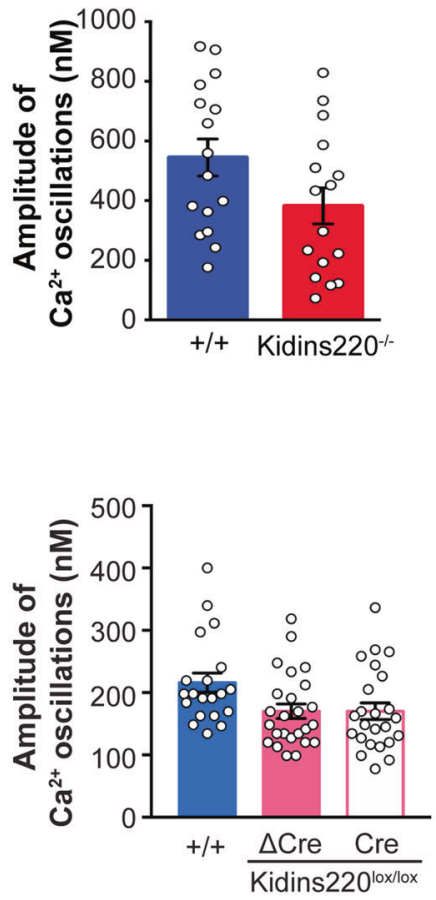

G

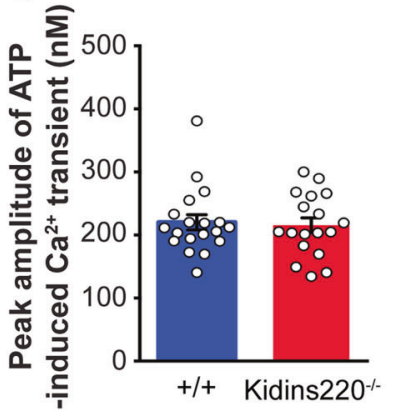

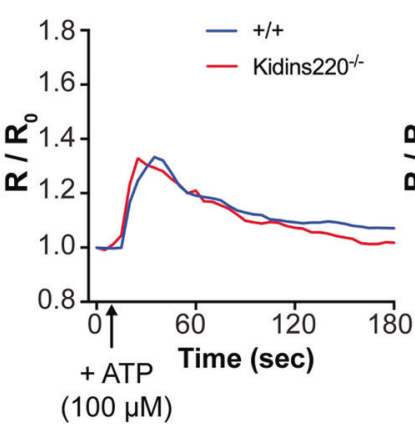

I

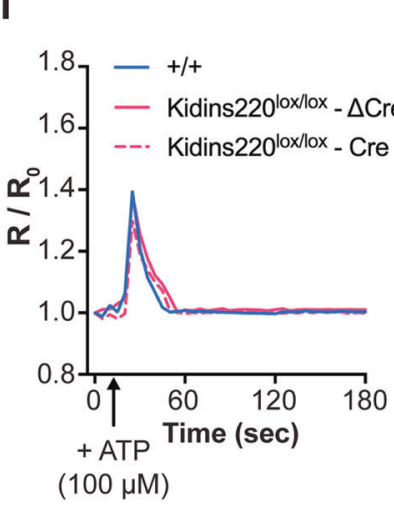

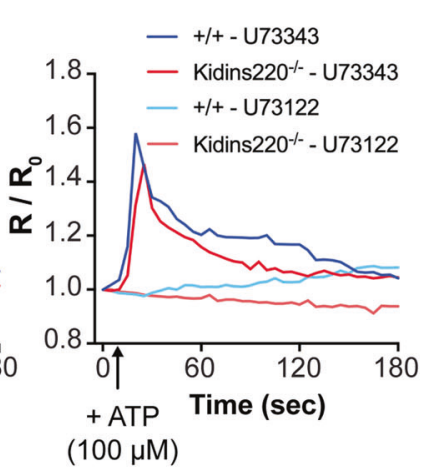

$(100 \mu \mathrm{M})$
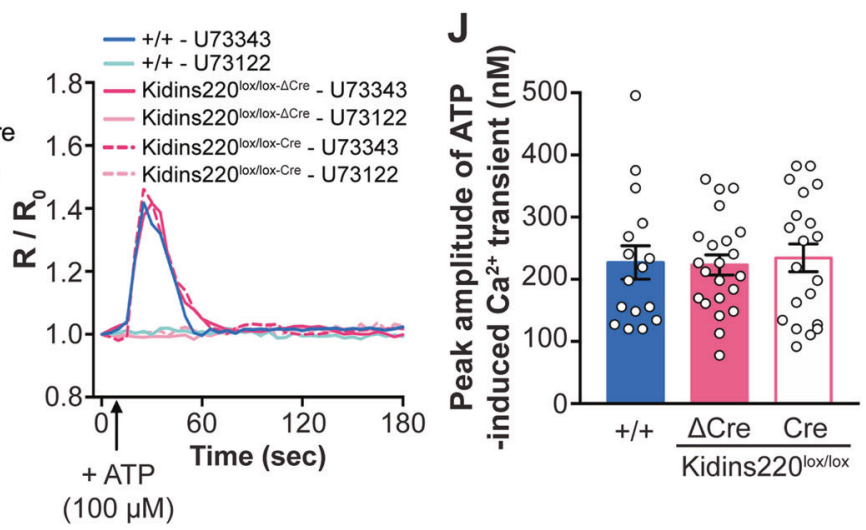
Fig. 1 Calcium signaling is impaired in Kidins $220^{-1-}$ embryo-derived astrocytes. a, b Spontaneous $\left[\mathrm{Ca}^{2+}\right]_{\mathrm{i}}$ transients in wild-type $(+/+)$ and Kidins $220^{-I-}$ embryonic astrocytes. a Representative spontaneous $\left[\mathrm{Ca}^{2+}\right]_{\mathrm{i}}$ oscillations recorded in wild-type (top panel, blue traces) and Kidins $220^{-1-}$ (bottom panel, red traces) astrocytes. b Percentage of spontaneously active cells (left), ${ }^{*} p<0.01$, unpaired Student's $t$ test, $n=6$ for both wild-type and Kidins $220^{-1-}$ cultures; frequency (middle) and amplitude (right) of spontaneous $\left[\mathrm{Ca}^{2+}\right]_{\mathrm{i}}$ oscillations in wildtype and Kidins $220^{-I-}$ astrocyte cultures. $p>0.05$, unpaired Student's $t$ test, $n=16$ for both wild-type and Kidins $220^{-1-}$ cells from six independent cultures. c, $\mathbf{d}$ Spontaneous $\left[\mathrm{Ca}^{2+}\right]_{\mathrm{i}}$ transients in wild-type $(+/+)$ and Kidins $220^{\text {lox/lox }} \mathrm{P} 0-\mathrm{P} 1$ astrocyte cultures infected with lentiviruses encoding catalytically dead $(\Delta \mathrm{Cre})$ or active Cre recombinase. c Representative spontaneous $\left[\mathrm{Ca}^{2+}\right]_{\mathrm{i}}$ oscillations recorded in wild-type (top panel, light blue traces), Kidins $220^{\operatorname{lox} / l o x}-\Delta$ Cre (middle panel, pink traces), and Kidins $220^{\text {lox/lox-Cre }}$ (bottom panel, dashed traces) astrocytes. d Percentage of spontaneously active cells (left), $p>0.05$, one-way ANOVA followed by Bonferroni's multiple comparison test $\left(n=4\right.$ and 6 for wild-type and Kidins $220^{\text {lox/lox }}$ cultures, respectively); frequency (middle) and amplitude (right) of spontaneous $\left[\mathrm{Ca}^{2+}\right]_{\mathrm{i}}$ oscillations in wild-type and Kidins $220^{\text {loxlox }}$ P0-P1 astrocyte cultures. $p>0.05$, one-way ANOVA followed by Bonferroni's multiple comparison test $\left(n=20,25\right.$, and 24 for wild-type, Kidins $220^{\text {lox/lox }-\Delta \text { Cre }}$, and Kidins $220^{\text {lox/lox }- \text { Cre }}$ cells from 4 to 6 independent cultures, respectively). e-g ATP-induced $\left[\mathrm{Ca}^{2+}\right]_{\mathrm{i}}$ signals in wild-type and Kidins $220^{--}$ astrocytes. e Percentage of cells displaying $\mathrm{Ca}^{2+}$ transients in response to ATP $(100 \mu \mathrm{M})$ stimulation. * $p<0.05$, unpaired Student's $t$ test, $n=6$ for both wild-type and Kidins $220^{-1-}$ cultures. $\mathbf{f}$ Kinetics of ATP-evoked $\left[\mathrm{Ca}^{2+}\right]_{\mathrm{i}}$ dynamics in wild-type and Kidins $220^{-/-}$astrocytes in the absence (left) or presence (right) of U73122 (PLC $\gamma$ inhibitor) or U73343 (inactive analog). g Amplitude of ATP-evoked $\left[\mathrm{Ca}^{2+}\right]_{\mathrm{i}}$ signal in wild-type and Kidins $220^{-1-}$ astrocytes. $p>0.05$, unpaired Student's $t$ test, $n=19$ wild-type and 18 Kidins $220^{-1-}$ cells from six independent cultures. $\mathbf{h}-\mathbf{j}$ ATP-induced $\left[\mathrm{Ca}^{2+}\right]_{\mathrm{i}}$ transients in wild-type and Kidins $220^{\text {lox/lox }}$ astrocytes. h Percentage of cells displaying $\left[\mathrm{Ca}^{2+}\right]_{\mathrm{i}}$ rise in response to ATP $(100 \mu \mathrm{M})$ stimulation $(n=4$ and 6 for wild-type and Kidins $220^{\text {lox/lox }}$ cultures, respectively). i Kinetics of ATP-evoked $\mathrm{Ca}^{2+}$ influx in wild-type and Kidins $220^{\text {lox/lox }}$ astrocytes in the absence (left) or presence (right) of U73122 (PLC $\gamma$ inhibitor) or U73343 (inactive analog). $\mathbf{j}$ Amplitude of ATP-evoked $\left[\mathrm{Ca}^{2+}\right]_{\mathrm{i}}$ signal in wildtype and Kidins $220^{\text {lox/lox }}$ astrocytes. $p>0.05$, one-way ANOVA followed by Bonferroni's multiple comparison test $(n=16,22$, and 20 for wild-type, Kidins $220^{\text {lox/lox- }-\Delta \text { Cre }}$, and Kidins $220^{\text {lox/lox-Cre }}$ cells from 4 to 6 independent cultures, respectively). Values are expressed as means \pm S.E.M. in all panels

embryonic cultures from Kidins $220^{-/-}$mice, suggesting that chronic loss of Kidins 220 causes developmental defects in primary cultured astrocytes.

\section{Kidins220 regulates the expression of plasma membrane proteins involved in $\left[\mathrm{Ca}^{2+}\right]_{i}$ signaling}

In the attempt to gain more mechanistic insights to explain the differential $\left[\mathrm{Ca}^{2+}\right]_{\mathrm{i}}$ responses observed in Kidins $220^{-/-}$ astrocytes, we next addressed the possibility that Kidins 220 ablation induces a derangement of the processes underlying $\left[\mathrm{Ca}^{2+}\right]_{\mathrm{i}}$ homeostasis. Whereas wild-type cells responding to ATP were characterized by a lower basal $\left[\mathrm{Ca}^{2+}\right]_{\mathrm{i}}$ concentration compared with not responding cells, this difference was not observed in Kidins $220^{-/-}$astrocytes, in which basal $\left[\mathrm{Ca}^{2+}\right]_{\mathrm{i}}$ levels were comparable between ATPresponding and non-responding cells, and were not significantly different from the wild-type groups (Fig. 2a). We then addressed the mechanism of store-operated $\mathrm{Ca}^{2+}$ entry (SOCE), which is a key determinant of $\left[\mathrm{Ca}^{2+}\right]_{\mathrm{i}}$ dynamics. Administration of thapsigargin, a specific inhibitor of the sarco/endoplasmic reticulum $\mathrm{Ca}^{2+}$-ATPase (SERCA), in the absence of extracellular $\mathrm{Ca}^{2+}$, induces an increase of $\left[\mathrm{Ca}^{2+}\right]_{\mathrm{i}}$ proportional to the depletion of the internal $\mathrm{Ca}^{2+}$ stores. Under these experimental conditions, $\left[\mathrm{Ca}^{2+}\right]_{\mathrm{i}}$ rises were lower in Kidins $220^{-/-}$astrocytes compared with wild type, strongly indicating that Kidins $220^{-/-}$astrocytes have an impairment of the $\mathrm{Ca}^{2+}$ release from intracellular stores. When $\mathrm{Ca}^{2+}(2 \mathrm{mM})$ is added back to the extracellular solution, the $\left[\mathrm{Ca}^{2+}\right]_{\mathrm{i}}$ increase is mediated by plasma membrane $\mathrm{Ca}^{2+}$ channels involved in store refilling via SOCE. Our data indicate that upon $\mathrm{Ca}^{2+}$ readmission, the $\left[\mathrm{Ca}^{2+}\right]_{\mathrm{i}}$ rise was also markedly reduced in Kidins $220^{-1-}$ astrocytes compared with wild-type cells (Fig. 2b). Altogether these results indicate that Kidins 220 is necessary for correct $\left[\mathrm{Ca}^{2+}\right]_{\mathrm{i}}$ signaling associated with SOCE in primary embryonic astrocytes.

To better understand the mechanisms underlying the observed dysregulation of spontaneous and evoked $\left[\mathrm{Ca}^{2+}\right]_{\mathrm{i}}$ oscillations in Kidins $220^{--}$astrocytes, we performed RT-qPCR on mRNAs extracted from wild-type and Kidins $220^{-1-}$ cultured astrocytes and analyzed the expression profile of a panel of channels and receptors involved in $\left[\mathrm{Ca}^{2+}\right]_{\mathrm{i}}$ dynamics (Fig. 2c). It is well known that ATP promotes an increase in $\left[\mathrm{Ca}^{2+}\right]_{\mathrm{i}}$ signaling in astrocytes by binding to purinergic receptors ( $\mathrm{P} 2)$ belonging to the ligandgated (P2X) and G-protein-coupled (P2Y) subtypes [40]. We therefore asked whether the decrease in the number of ATP-responding cells was due, at least in part, to altered expression of ATP receptors, and found downregulation of the transcripts for P2Y1, P2Y2, and P2X1, and upregulation of P2X5. Since our data showed a decrement in SOCE efficiency in Kidins $220^{-1-}$ astrocytes, we next investigated the expression levels of proteins known to be involved in SOCE. No significant changes were observed in the transcript levels of SERCA2, of STIM1/2, the major endoplasmic proteins coupled to store refilling mechanisms at the plasma membrane [41], and of the inositol-1,4,5-triphosphate $\left(\mathrm{IP}_{3}\right)$ receptor subtype $2\left(\mathrm{IP}_{3} \mathrm{R} 2\right)$, which is specifically expressed in astrocytes [42, 43] and coupled to purinergic receptor activity [44]. The expression of voltagegated $\mathrm{Ca}^{2+}$ channels in astrocytes has been reported in cultured astrocytes and in situ at least at the molecular level ([40] and references therein). We found detectable expression of various subtypes of voltage-gated $\mathrm{Ca}^{2+}$ channels in wild-type astrocytes, which were differentially affected by the absence of Kidins220. Indeed, Kidins $220^{-1-}$ cells were 

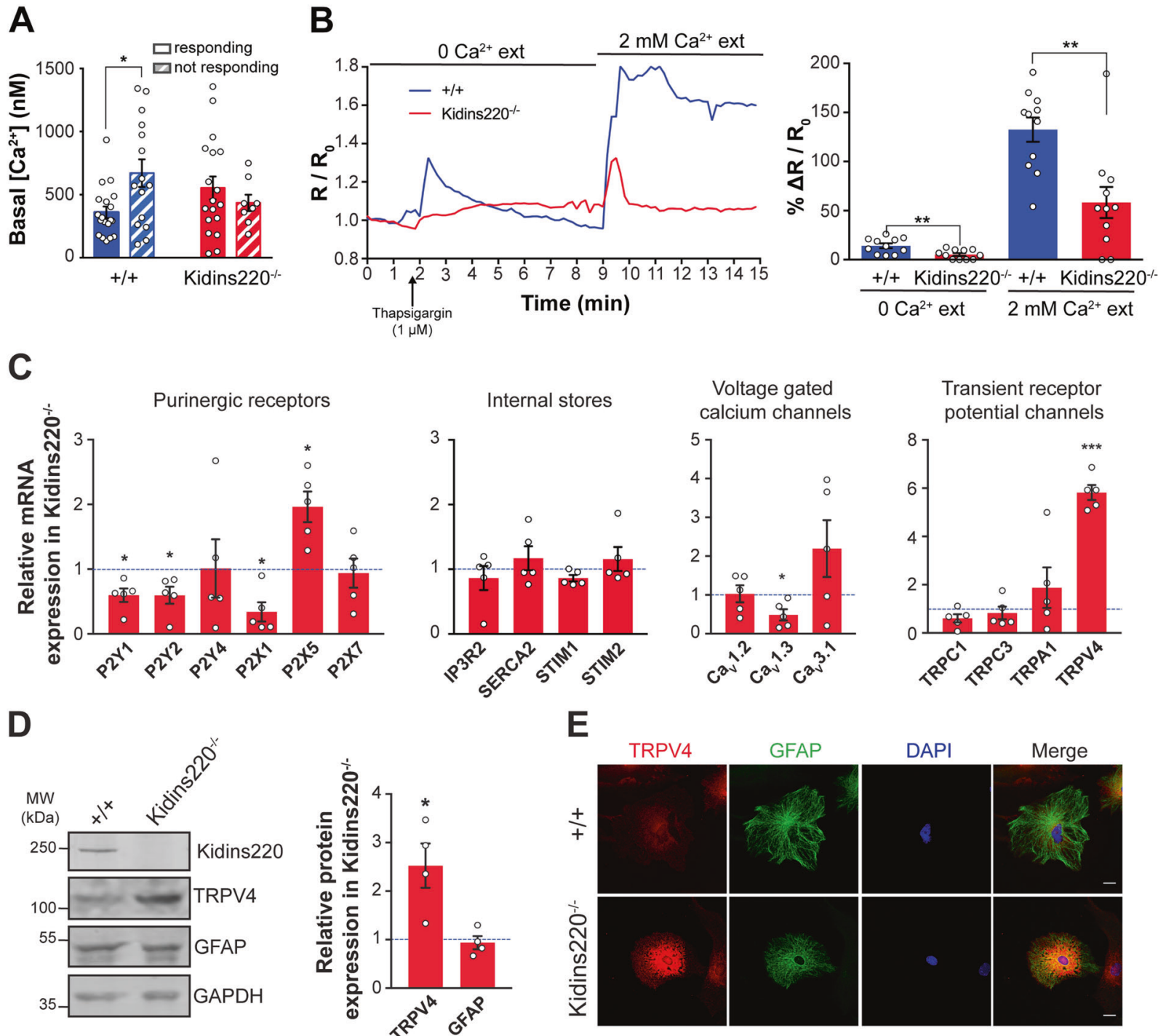

$\mathbf{F}$
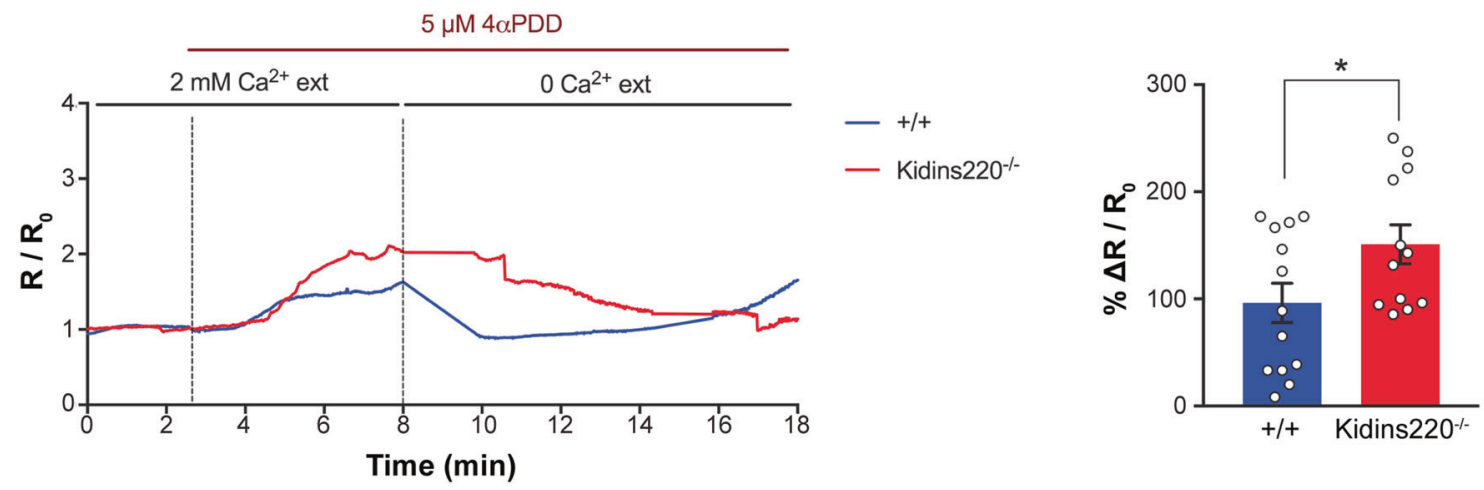

characterized by decreased expression of $\mathrm{Ca}_{\mathrm{v}} 1.3$, but not of $\mathrm{Ca}_{\mathrm{v}} 1.2$ (L-type $\mathrm{Ca}^{2+}$ channels) and of $\mathrm{Ca}_{\mathrm{v}} 3.1$ (T-type $\mathrm{Ca}^{2+}$ channel). Astrocytes are also endowed with a variety of ion channels that permeate $\mathrm{Ca}^{2+}$ and monovalent cations, called transient receptor potential (TRP), which are involved in the modulation of $\left[\mathrm{Ca}^{2+}\right]_{\mathrm{i}}$ dynamics and play a role in SOCE
[40]. Some of those are involved in agonist-mediated $\left[\mathrm{Ca}^{2+}\right]_{\mathrm{i}}$ dynamics, or play a role in spontaneous $\left[\mathrm{Ca}^{2+}\right]_{\mathrm{i}}$ oscillations [45]. The transcript levels of TRPC1, TRPC 3 and TRPA1, were not significantly altered in Kidins $220^{-/-}$astrocytes. Notably TRPV4, which is expressed in cultured astrocytes and mediates $\left[\mathrm{Ca}^{2+}\right]_{\mathrm{i}}$ signaling [46], showed a remarkable 
Fig. 2 Defects in SOCE and increased expression of the TRPV4 calcium channel are detected in Kidins $220^{-/-}$astrocytes. a Basal $\left[\mathrm{Ca}^{2+}\right]_{\mathrm{i}}$ concentration measured in wild-type and Kidins $220^{-/-}$astrocytes responding and non-responding to ATP. ${ }^{*} p<0.05$, one-way ANOVA followed by Bonferroni's multiple comparison test ( $n=34$ wild-type and 26 Kidins $220^{-1-}$ cells from six independent cultures). b Thapsigargin-induced intracellular $\left[\mathrm{Ca}^{2+}\right]_{\mathrm{i}}$ responses in wild-type and Kidins $220^{-I-}$ astrocytes. Representative traces (left) and quantification of fluorescence intensity (right) of thapsigargin $(1 \mu \mathrm{M})$-treated wildtype or Kidins $220^{-1-}$ astrocytes, in the presence or absence of $2 \mathrm{mM}$ external $\mathrm{Ca}^{2+}$, as indicated. $* * p<0.01$, unpaired Student's $t$ test $(n=$ 11 wild-type and Kidins $220^{-1-}$ cells from two independent cultures). c mRNA expression profile of $\mathrm{Ca}^{2+}$ signaling proteins in Kidins $220^{-/-}$ astrocyte cultures. mRNA expression of Kidins $220^{-1-}$ samples was normalized to the values of wild-type samples within the same RTqPCR plate. $* p<0.05, * * * p<0.001$, one-sample $t$-test $(n=5$ for both wild-type and Kidins $220^{-1-}$ cultures). d Protein extracts from wildtype and Kidins $220^{-1-}$ astrocyte cultures at 15 DIV were analyzed by western blotting using anti-Kidins220, anti-TRPV4, and anti-GFAP antibodies. GAPDH was used as a loading control. A representative immunoblot is shown on the left; quantification of TRPV4 and GFAP expression levels is shown on the right. The intensity of the bands from Kidins $220^{-1-}$ samples was normalized to the corresponding bands from wild-type samples within the same nitrocellulose membrane. ${ }^{*} p<0.05$, one-sample $t$-test $(n=4$ for both wild-type and Kidins $220^{-1-}$ cultures). e Representative confocal images of wild-type and Kidins $220^{-1-}$ astrocytes stained with anti-TRPV4 and anti-GFAP antibodies, and with DAPI to visualize nuclei. Scale bars, $20 \mu \mathrm{m}$. f $4 \alpha$ PDD-induced intracellular $\mathrm{Ca}^{2+}$ influx in wild-type and Kidins $220^{-1-}$ astrocytes. Representative traces (left) and quantification of fluorescence intensity (right) of $4 \alpha \operatorname{PDD}(5 \mu \mathrm{M})$-treated wild-type and Kidins $220^{-1-}$ astrocytes, in the presence or absence of $2 \mathrm{mM}$ external $\mathrm{Ca}^{2+}$, as indicated. Quantification was performed at the plateau at $2 \mathrm{mM} \mathrm{Ca}^{2+}$, averaging values between 6 and $8 \mathrm{~min} . * p<0.05$, unpaired Student's $t$ test ( $n=13$ wild-type and $n=12$ Kidins $220^{-/-}$ cells from three independent cultures). Values are expressed as means \pm S.E.M. in all panels

six-fold increase in Kidins $220^{-/-}$astrocytes, compared with wild-type cells. We furthermore addressed whether transcription of $\mathrm{Ca}^{2+}$-related proteins was altered also in postnatal cultures, and confirmed the reduced P2Y1 and P2Y2 and the increased TRPV4 expression (Fig. S2C).

The large upregulation of TRPV4 expression was corroborated by western blot and immunostaining analyses (Fig. 2d, e). Likewise stimulation of cultured astrocytes with $4 \alpha$ PDD, a specific TRPV4 agonist that was shown to increase $\left[\mathrm{Ca}^{2+}\right]_{\mathrm{i}}$ in astrocytes [47], caused higher $\left[\mathrm{Ca}^{2+}\right]_{\mathrm{i}}$ responses in Kidins $220^{-1-}$ astrocytes compared with wild-type cells (Fig. 2f). Altogether these results indicate that the absence of Kidins 220 in astrocytes leads to alterations of $\left[\mathrm{Ca}^{2+}\right]_{i}$ signaling through dysregulation of $\mathrm{Ca}^{2+}$-permeable proteins on both the endoplasmic and plasma membranes. Since overall the changes induced by Kidins 220 depletion were more evident in the Kidins $220^{-1-}$ system, we proceeded by analyzing the functional outcomes of the observed deficits on cell survival and astrocyte-to-neuron communication by performing experiments on constitutively knocked out cells.

\section{Kidins $220^{-I-}$ astrocytes are more sensitive to genotoxic stress}

$\mathrm{Ca}^{2+}$-dependent pathways are crucial to shape astrocyte responsiveness to extracellular cues, ultimately determining the activation of survival or death pathways [48]. We thus asked whether the described alterations in the $\left[\mathrm{Ca}^{2+}\right]_{\mathrm{i}}$ system could have an impact on the viability of Kidins $220^{-1-}$ cells. To this aim, the percentage of active caspase 3positive apoptotic cells was quantified after exposure to either oxidative or genotoxic stress, triggered by $\mathrm{H}_{2} \mathrm{O}_{2}$ or UVB exposure, respectively. While no differences in the number of apoptotic cells were evident under basal conditions, cells showed different sensitivity to stressing stimuli in the absence of Kidins220. Oxidative stress-induced cell death did not depend on the presence of Kidins 220 (Fig. 3a), while the percentage of dying cells in cultures exposed to UVB $\left(25 \mathrm{~mJ} / \mathrm{cm}^{2}\right)$ was strongly increased in Kidins $220^{-1-}$ astrocytes (Fig. 3b). No significant differences between wild-type and Kidins $220^{-1-}$ cells were observed at a higher dose of UVB, suggesting the presence of a ceiling effect in apoptosis induction irrespective of genotype. Altogether, these results suggest that Kidins 220 is involved in the regulation of astrocyte survival capabilities under specific conditions.

\section{Kidins220 expression in astrocytes is required for proper neuronal development}

To investigate the consequences of Kidins 220 depletion in astrocytes on neuronal development, wild-type neurons were plated on wild-type or Kidins $220^{-1-}$ astrocytes and their dendritic development was analyzed by Sholl analysis at 3 DIV. This analysis revealed that the complexity of the dendritic tree of the neurons grown on astrocytes depleted of Kidins220 was reduced compared with neurons grown on wild-type astrocytes, with reduction of branching and decrease in the total dendritic length (Fig. 4a). We then asked whether this morphological alteration was associated with defective synaptic development, and analyzed the formation of glutamatergic and GABAergic synaptic connections in these neuron-astrocyte cocultures by quantifying the density of VGLUT1 and VGAT boutons, respectively, at 5, 7, and 10 DIV. While the formation of glutamatergic synapses was comparable across genotypes at all the developmental stages, the density of VGAT boutons was delayed, being decreased at the earliest stage analyzed (Fig. 4b, c).

To investigate whether the absence of Kidins 220 in astrocytes would also affect the functionality of a cocultured neuronal network, we analyzed the excitability of neurons in coculture with wild-type or Kidins $220^{-/-}$cells by recording AP firing in response to $500 \mathrm{~ms}$ stepwise injection 
Fig. 3 Kidins $220^{-/-}$astrocytes are more sensitive to genotoxic stress. Wild-type and Kidins $220^{-1-}$ astrocyte cultures at $15 \mathrm{DIV}$ were treated with 100 or $300 \mu \mathrm{M} \mathrm{H}_{2} \mathrm{O}_{2}$ for $30 \mathrm{~min}$ (a) or exposed to 25 or $50 \mathrm{~mJ} / \mathrm{cm}^{2}$ UVB (b), fixed and stained with anti-active caspase 3 antibodies. Left: representative images of treated cultures; arrows indicate active caspase 3-positive apoptotic cells. Scale bar, $50 \mu \mathrm{m}$. Right: quantification of percentage of apoptotic cells after $\mathrm{H}_{2} \mathrm{O}_{2}$ or UVB treatment. $* p<0.05$, unpaired Student's $t$ test $(n=3$ (a) and $n=4$ (b) for both wild-type and Kidins $220^{-1-}$ cultures). Values are expressed as means \pm S.E. M. in all panels
A

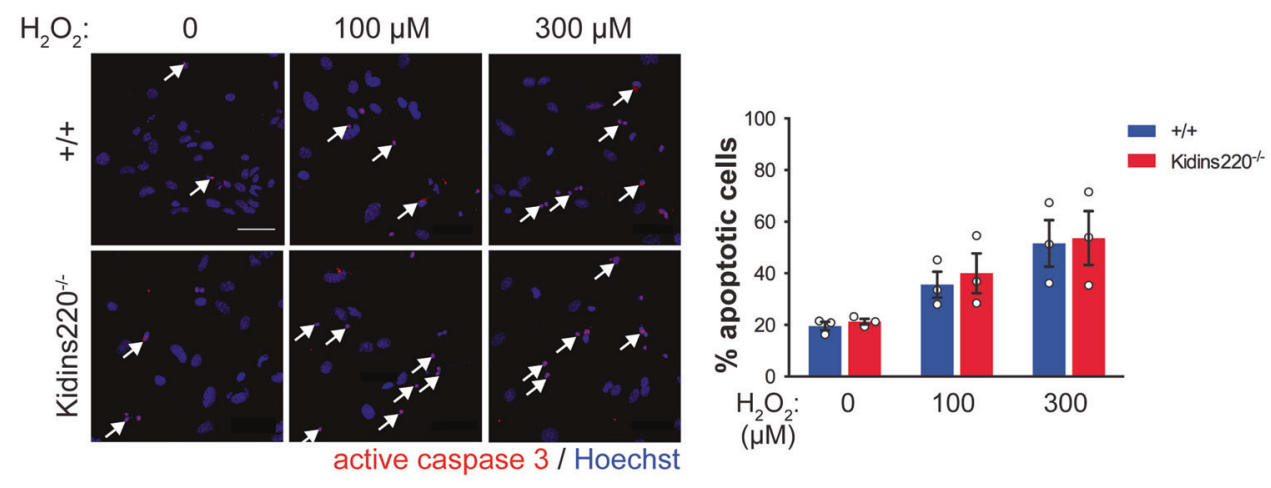

B

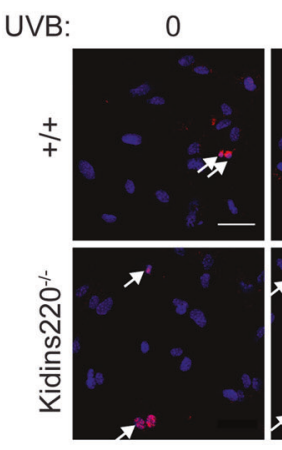

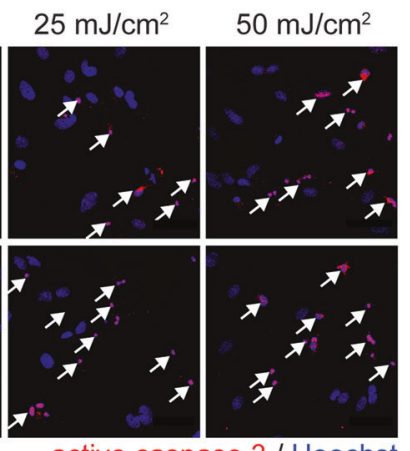

active caspase 3 / Hoechst

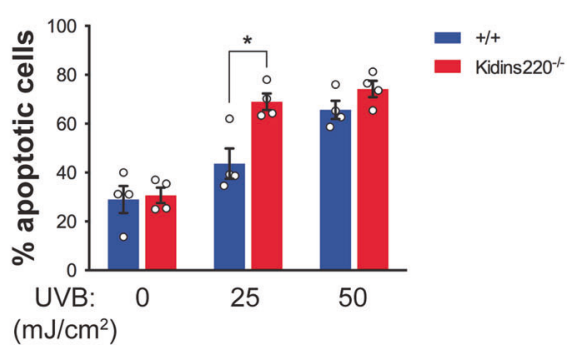

of current of increasing amplitude by whole cell patchclamp in the current-clamp configuration (Fig. 5a). These experiments revealed a decrease in both evoked firing and instantaneous firing frequency for wild-type neurons grown on Kidins $220^{-/-}$astrocytes, accompanied by a significantly higher rheobase (Table $\mathrm{S} 2$ ), indicating a general reduction of network excitability when Kidins $220^{-1-}$ astrocytes are used as feeder layer. Overall, these data suggest that Kidins 220 expression in astrocytes is required for the establishment of proper neuronal excitability.

To determine whether the observed defects in neuronal development were contact-dependent or the consequence of impaired secretion of gliotrophic factors, the same experiments were performed on wild-type neurons cultured in astrocyte-conditioned medium (ACM) derived from either wild-type or Kidins $220^{-1-}$ cultures. In the absence of a physical contact with astrocytes, neurons were overall less excitable (rheobase $105.55 \pm 22.42$ versus $71.11 \pm 11.60 \mathrm{pA}$ in the presence of astrocytes). However, the firing response to current injection was still decreased when neurons were cultured in the ACM from Kidins $220^{-1-}$ cells (Fig. 5b), suggesting that the effect on neuronal development was dependent on the paracrine action of gliotransmitters. In order to identify the astrocyte-secreted factor(s) involved in this process, the concentrations of BDNF, glutamine, and ATP were measured by ELISA in culture supernatants from wildtype and Kidins $220^{-I-}$ astrocytes (Fig. 5c). While both
BDNF and glutamine levels were not affected, a marked reduction in ATP concentration in Kidins $220^{-1-}$ supernatants was observed. Taken together, these data showed that Kidins220 expression in astrocytes is required for the secretion of gliotransmitters that are necessary for proper neuronal development.

\section{Discussion}

With this work, we extended the knowledge about the function of the scaffolding protein Kidins220, so far limited to neurons [23, 24], to primary astrocytes. Kidins $220^{-/-}$ embryos-derived cells display impaired $\left[\mathrm{Ca}^{2+}\right]_{i}$ dynamics under basal conditions and upon ATP stimulation showing that, in line with what was shown in the immune system $[49,50]$, Kidins 220 modulates $\left[\mathrm{Ca}^{2+}\right]_{\mathrm{i}}$ responses in cultured astrocytes. Although the precise mechanisms underlying this $\left[\mathrm{Ca}^{2+}\right]_{\mathrm{i}}$ alterations remain to be determined, our data suggest that the $\left[\mathrm{Ca}^{2+}\right]_{\mathrm{i}}$ signaling defects observed in the absence of Kidins 220 are the consequence of the altered expression of several proteins involved in $\mathrm{Ca}^{2+}$ dynamics such as purinergic receptors and voltage-gated $\mathrm{Ca}^{2+}$ channels. SOCE is an essential mechanisms to maintain $\left[\mathrm{Ca}^{2+}\right]_{\mathrm{i}}$ homeostasis in every cell type, including astrocytes [51], where it controls the variations of $\left[\mathrm{Ca}^{2+}\right]_{i}$ that underlie $\mathrm{Ca}^{2+}$ signaling and gliosecretion in response to extracellular 
A
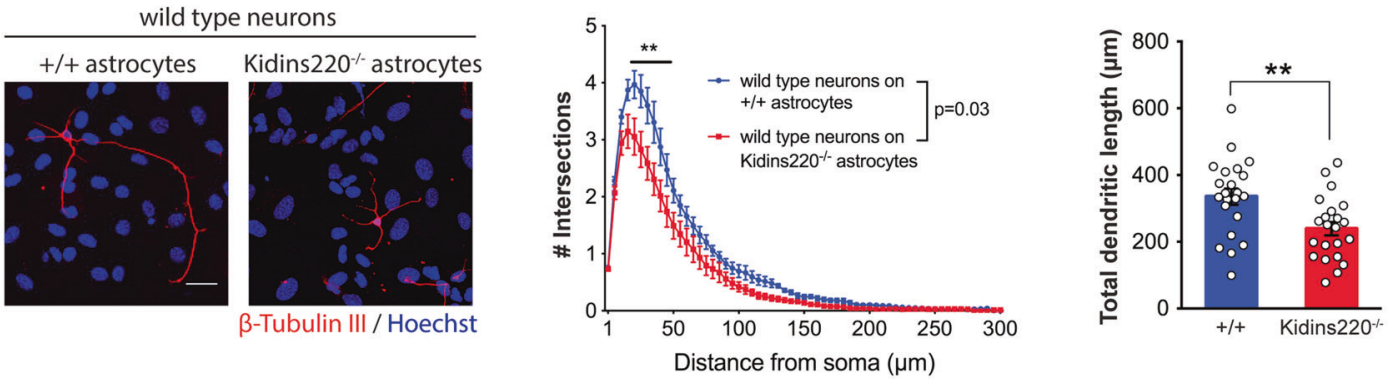

B

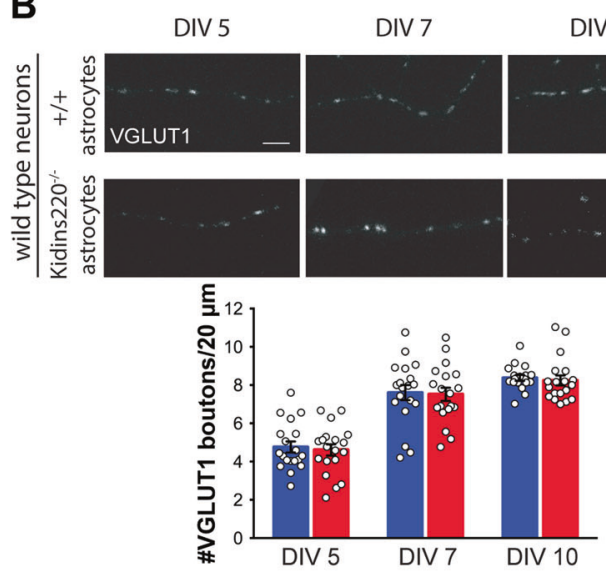

Fig. 4 Kidins 220 expression in astrocytes is required for proper neuronal development. a Wild-type neurons were plated on confluent wild-type $(+/+)$ or Kidins $220^{-/-}$astrocyte cultures, fixed and stained with anti- $\beta$ tubulin III antibodies after 3 DIV to visualize, and quantify network development. Left: representative images of neuron-astrocyte cocultures. Scale bar, $25 \mu \mathrm{m}$. Middle: Sholl analysis of wild-type neurons grown on either wild-type or Kidins $220^{-1-}$ astrocytes for 3 DIV. Genotype effect: $p=0.03$; ** $p<0.01$, repeated measures ANOVA followed by the Bonferroni's multiple comparison test $(n=5$ for both wild-type and Kidins $220^{-1-}$ cultures). Right: total dendritic length of wild-type neurons grown on either wild-type or

stimuli $[52,53]$. Kidins $220^{-/-}$astrocytes are characterized by altered expression of several genes involved in the regulation of $\mathrm{Ca}^{2+}$ influx from the intracellular stores and in SOCE, and display a remarkable increase in the expression of TRPV4, a member of the vanilloid subfamily of $\mathrm{Ca}^{2+}$ channels that is thermo-, osmo-, and mechano-sensitive [54-56]. TRPV4 channels mediate $\mathrm{Ca}^{2+}$ influx in primary astrocytes [46, 47] and promote $\mathrm{Ca}^{2+}$-dependent $\mathrm{Ca}^{2+}$ release [57]. In Kidins $220^{-1-}$ astrocytes, the increased TRPV4 expression is associated with a decreased efficiency of $\left[\mathrm{Ca}^{2+}\right]_{\mathrm{i}}$ regulation and could, at least partially, compensate for the defective $\left[\mathrm{Ca}^{2+}\right]_{\mathrm{i}}$ homeostasis. Moreover, since TRPV4 contributes to the astrocyte responses to various pathological stimuli $[47,58]$, its increased levels could be the expression of the astrocyte reaction to the stressing environment generated by the lack of Kidins 220 . Notably, $\left[\mathrm{Ca}^{2+}\right]_{\mathrm{i}}$ deregulation in Kidins $220^{-1-}$ astrocytes was not associated with a significant variation in other ionic parameters relevant to the homeostatic mechanisms of astroglial
C

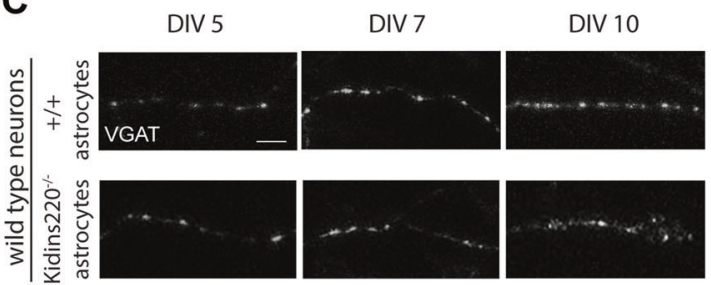

wild type neurons on $+/+$ astrocytes wild type neurons on Kidins $220^{-1}$ astrocytes

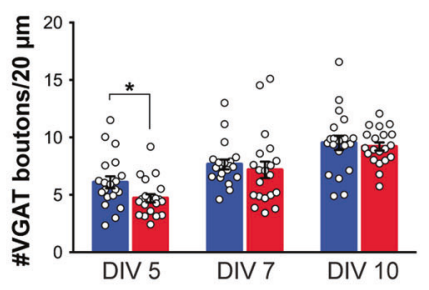

Kidins $220^{-1-}$ astrocytes for 3 DIV. $* * p<0.01$, unpaired Student's $t$ test $\left(n=22\right.$ wild-type and Kidins $220^{-l-}$ cells from five independent cultures). Upper panels: representative images of wild-type neurons plated on confluent wild-type or Kidins $220^{-1-}$ astrocyte cultures stained with anti-VGLUT1 (b) or anti-VGAT (c) antibodies at 5, 7, and 10 DIV. Scale bars, $5 \mu \mathrm{m}$. Lower panels: quantification of the density of VGLUT1 and VGAT-positive boutons under the various experimental conditions. ${ }^{*} p<0.05$, unpaired Student's $t$ test $(n=20$ wild-type and Kidins $220^{-1-}$ cells from five independent cultures). Values are expressed as means \pm S.E.M. in all panels

cells, as shown by the observation that the plasma membrane potassium $\left(\mathrm{K}^{+}\right)$conductance was not significantly different between the wild-type and Kidins $220^{-/-}$cells (Fig. S3). This result adds support to the view that the absence of Kidins $220^{-1-}$ in astrocytes specifically affects only some of the signaling processes involved in the functional capacity of astroglial cells. Interestingly, Kidins 220 depletion has different consequences on $\left[\mathrm{Ca}^{2+}\right]_{\mathrm{i}}$ homeostasis depending on the stage of the cells. Indeed, Cre-induced depletion of Kidins220 in postnatal astrocytes did not cause appreciable alterations of spontaneous and stimulus-induced $\left[\mathrm{Ca}^{2+}\right]_{i}$ dynamics. Astrocytes undergo important physiological changes from the embryonic development to the postnatal period, accompanied by variations in the expression pattern of several signaling proteins [59]. The molecular underpinnings of such diverse scenarios are currently under investigation.

$\left[\mathrm{Ca}^{2+}\right]_{\mathrm{i}}$ oscillations also plays a fundamental role in maintaining the tight balance between pro-survival and pro- 
A
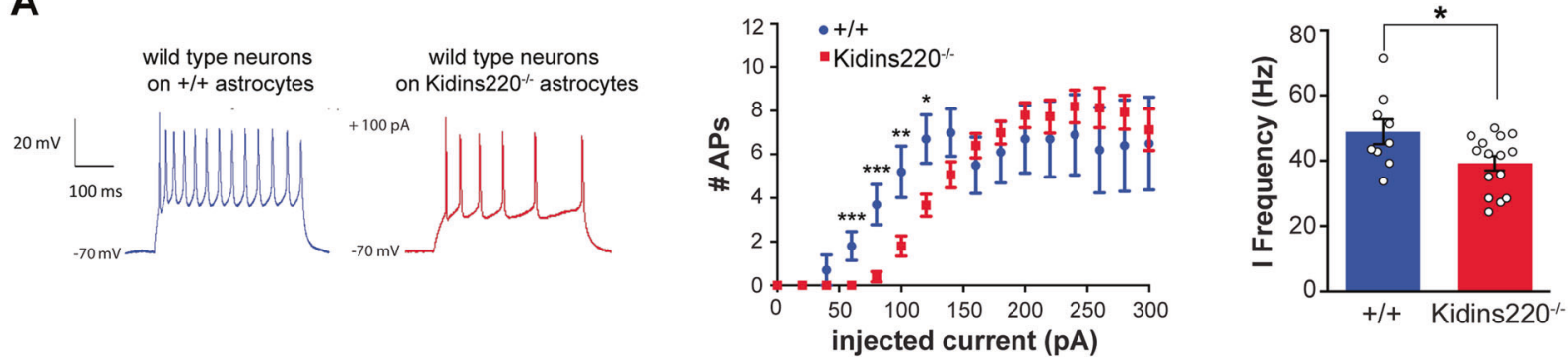

B
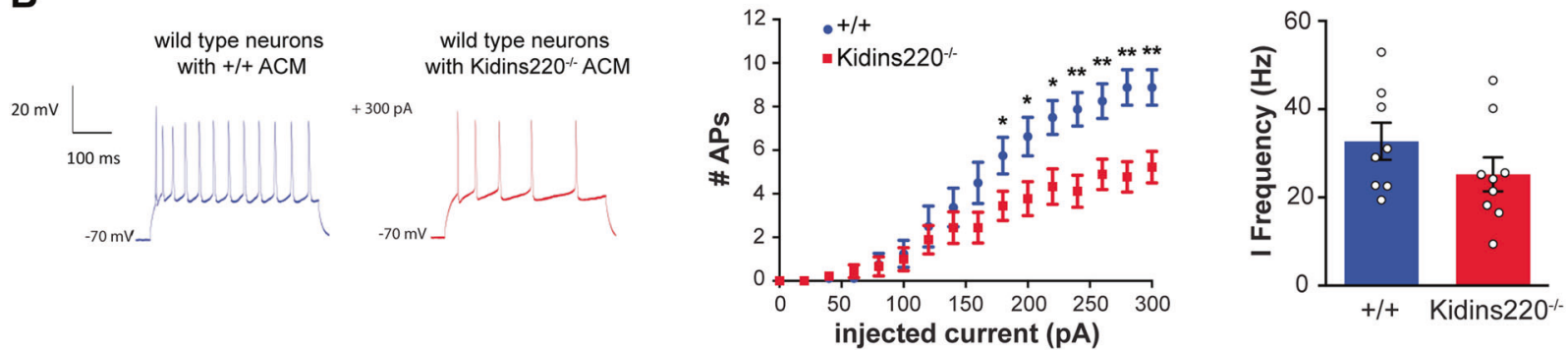

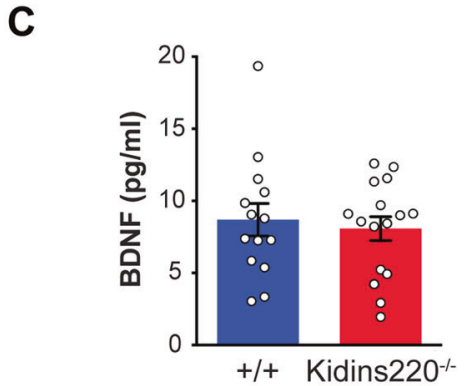

Fig. 5 Kidins 220 expression in astrocytes is required for proper neuronal maturation. a Firing properties of wild-type neurons grown on either wild-type or Kidins $220^{-1-}$ astrocytes for 14 DIV. Left: representative firing traces in response to current injection. Middle: number of action potential versus injected current. Right: instantaneous frequency calculated from the first interspike interval. ${ }^{*} p<0.05, * * p<0.01, * * * p<0.001$, unpaired Student's $t$ test $(n=9$ wild-type neurons on wild-type astrocytes, and $n=15$ wild-type neurons on Kidins $220^{-/-}$astrocytes, from three independent preparations). b Firing properties of wild-type neurons grown for 14 DIV in astrocyte-conditioned medium (ACM) from either wild-type $(+/+)$ or

apoptotic pathways [48]. Our results demonstrate that survival pathways are affected by the lack of Kidins220; interestingly, this does not lead to a general decrease of cell viability, but it rather selectively affects the sensitivity of astrocytes to genotoxic stress. These results are consistent with previous studies showing that depletion of Kidins 220 facilitates UV irradiation-induced apoptotic death in melanoma cells [60], and suggest that Kidins 220 is involved in the modulation of cell survival only under specific stressing conditions. Kidins 220 has been identified as an oncogene, affecting the ability of cells to survive, proliferate, and migrate/metastasize in several cancer types, including melanoma [60] and neuroblastoma [61-63]. On the basis of our results, we hypothesize that alteration of Kidins 220 levels is a pathogenic event that can modify the physiological equilibrium between survival and death pathways. The

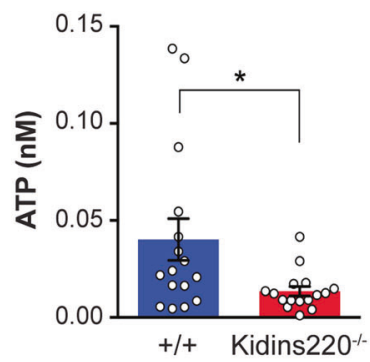

Kidins $220^{-1-}$ astrocytes. Left: representative firing traces in response to current injections. Middle: number of action potential frequency versus injected current. Right: instantaneous firing frequency of the first action potential. $* p<0.05, * * p<0.01$, unpaired Student's $t$ test ( $n=8$ wild-type neurons on wild-type astrocytes, and $n=9$ wild-type neurons on Kidins $220^{-1-}$ astrocytes, from two independent cultures). c Quantification of BDNF (left), glutamine (middle), and ATP (right) concentrations in culture supernatants from wild-type and Kidins $220^{-I-}$ astrocyte cultures at 15 DIV. ${ }^{*} p<0.05$, unpaired Student's $t$ test ( $n=16$ for both wild-type and Kidins $220^{-1-}$ cultures). Values are expressed as means \pm S.E.M. in all panels

relevance of defective $\left[\mathrm{Ca}^{2+}\right]_{\mathrm{i}}$ dynamics in the observed alteration in survival of Kidins $220^{-/-}$astrocytes remains to be established and warrants further investigation.

Astrocytic $\left[\mathrm{Ca}^{2+}\right]_{\mathrm{i}}$ transients play a crucial role in the bidirectional communication with neurons, and alterations of $\left[\mathrm{Ca}^{2+}\right]_{\mathrm{i}}$-dependent intracellular signaling may have a strong impact on neuronal survival and functionality [5, 6, 64]. Indeed, wild-type neurons grown onto Kidins $220^{-1-}$ astrocytes display neuronal development and maturation defects compared with neurons grown on wildtype glial cells, as illustrated by the reduced branching and delay in the formation of inhibitory synapses; moreover they are less excitable, as shown by the decrease in firing frequency over a range of injected currents. Interestingly, a similar reduction in excitability was observed when primary neurons were cultured in Kidins $220^{-l-}$ astrocyte-derived 
Fig. 6 Main roles of Kidins 220 in astrocytes. Removal of Kidins 220 in astrocytes leads to defects in calcium-dependent signaling, which are accompanied by changes in the expression of several proteins involved in $\left[\mathrm{Ca}^{2+}\right]_{\mathrm{i}}$ dynamics, including TRPV4 channels (1) and by an impaired secretion of gliotransmitters necessary for proper neuronal development (2)
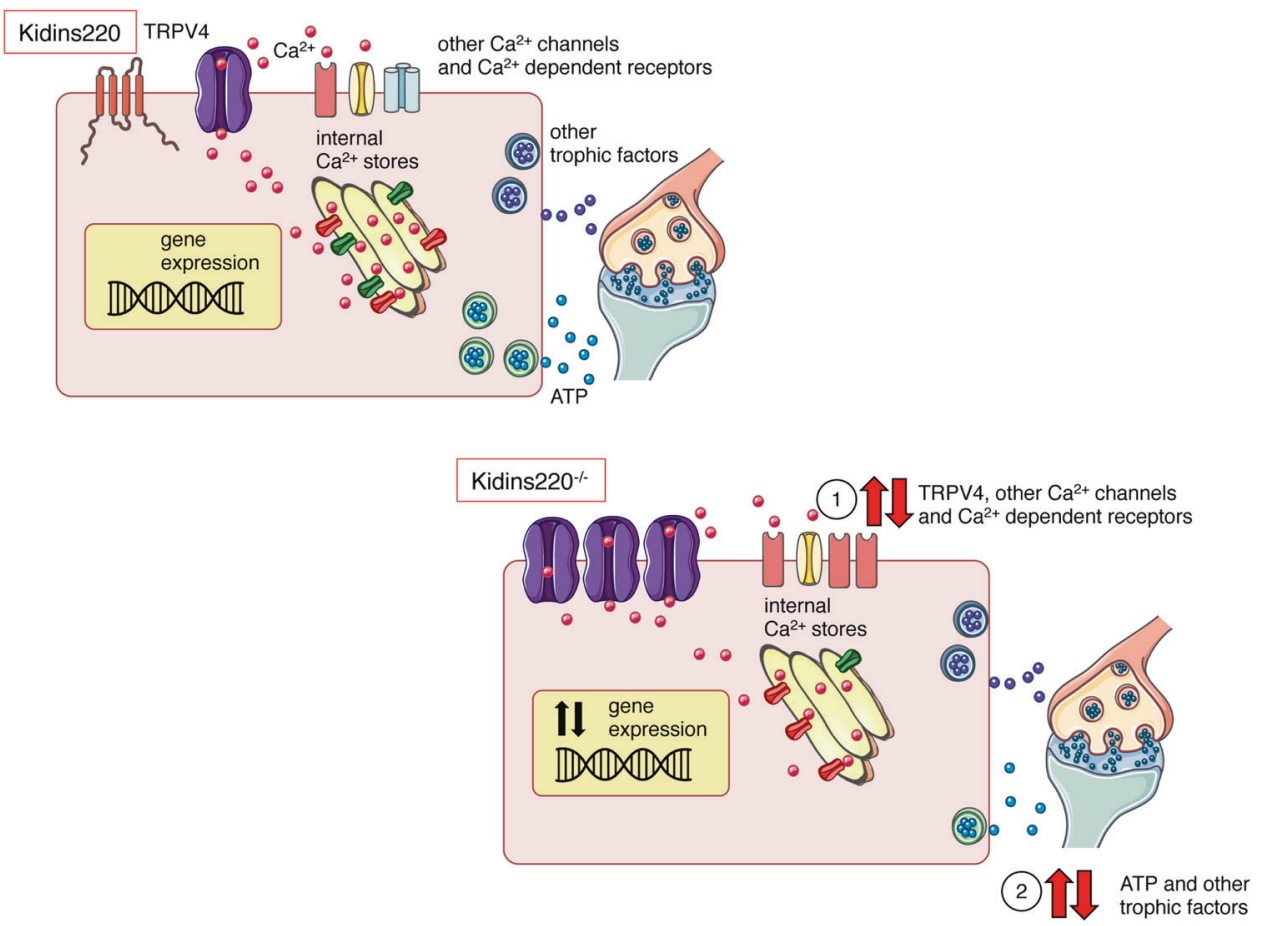

conditioned medium. Thus, even if we cannot exclude a contact-dependent effect, our results indicate that the observed neuronal deficits in the maturation of excitability are mainly due to impaired paracrine communication between astrocytes and neurons. Indeed, among various potential candidates, we found a significant reduction in ATP concentration in the culture medium conditioned by Kidins $220^{-/-}$astrocytes. ATP released from glia has diverse modulatory roles in synaptic transmission, including excitatory neurotransmission and depression of synaptic release by activation of presynaptic $\mathrm{A} 1$ adenosine receptors [65-67]. However, ATP, being released during $\mathrm{Ca}^{2+}$ wave propagation, is also a dominant gliotransmitter involved in astrocyte-to-astrocyte communication [7, 68]. Therefore, the observed neuronal defects could be ascribable to a direct action of ATP on neuronal physiology and/or to impaired ATP-dependent secretion of other gliotransmitters still to be identified.

In conclusion, our results deepen our understanding of how astrocytes regulate neuronal circuit development and function and identify Kidins 220 as a novel modulator of astrocyte physiology. Figure 6 offers a schematic representation of the main results of our work: according to our data, Kidins 220 acts by modulating $\mathrm{Ca}^{2+}$-mediated intracellular signaling cascades. Such alterations are accompanied by changes in the transcription profile of several components of the $\left[\mathrm{Ca}^{2+}\right]_{\mathrm{i}^{-}}$ signaling network, including TRPV4 channels, and by altered gliosecretion, which would impact on the physiology of neighboring neurons. In summary, Kidins220 appears to coordinate $\left[\mathrm{Ca}^{2+}\right]_{\mathrm{i}}$ dynamics underlying both astrocyte survival and astrocyte-to-neuron communication. In recent years, nonsense mutations in the KIDINS220 gene have been associated with the onset of severe neurological diseases in humans [69, 70]. These pathologies have been described as mostly neuronal conditions, however the contribution of astrocytes to the onset and development of these diseases should not be overlooked. In this light, our data provide the basis for further investigations aimed at addressing the differential contribution of Kidins 220 mutant neurons and glial cells to human pathologies.

Acknowledgements A. Mehilli, D. Moruzzo, F. Canu, and I. Dallorto are kindly acknowledged for their technical and administrative support. This work was supported by a grant from the Compagnia di San Paolo (grant \#2013.1014 to FC).

\section{Compliance with ethical standards}

Conflict of interest The authors declare that they have no conflict of interest.

Publisher's note Springer Nature remains neutral with regard to jurisdictional claims in published maps and institutional affiliations.

\section{References}

1. Ullian EM, Christopherson KS, Barres BA. Role for glia in synaptogenesis. Glia. 2004;47:209-16.

2. Verkhratsky A, Matteoli M, Parpura V, Mothet JP, Zorec R. Astrocytes as secretory cells of the central nervous system: idiosyncrasies of vesicular secretion. EMBO J. 2016;35:239-57.

3. Schipke CG, Kettenmann H. Astrocyte responses to neuronal activity. Glia. 2004;47:226-32. 
4. Volterra A, Meldolesi J. Astrocytes, from brain glue to communication elements: the revolution continues. Nat Rev Neurosci. 2005;6:626-40.

5. Bazargani N, Attwell D. Astrocyte calcium signaling: the third wave. Nat Neurosci. 2016;19:182-9.

6. Volterra A, Liaudet N, Savtchouk I. Astrocyte $\mathrm{Ca}(2)(+)$ signalling: an unexpected complexity. Nat Rev Neurosci. 2014;15:327-35.

7. Parpura V, Zorec R. Gliotransmission: exocytotic release from astrocytes. Brain Res Rev. 2010;63:83-92.

8. Pinto-Duarte A, Roberts AJ, Ouyang K, Sejnowski TJ. Impairments in remote memory caused by the lack of Type 2 IP3 receptors. Glia. 2019;67:1976-89.

9. Adamsky A, Kol A, Kreisel T, Doron A, Ozeri-Engelhard N, Melcer T, et al. Astrocytic activation generates de novo neuronal potentiation and memory enhancement. Cell. 2018;174:59-71 e14.

10. Robin LM, Oliveira da Cruz JF, Langlais VC, Martin-Fernandez M, Metna-Laurent M, Busquets-Garcia A, et al. Astroglial CB1 receptors determine synaptic D-serine availability to enable recognition memory. Neuron. 2018;98:935-44e5.

11. Verkhratsky A. Astroglial calcium signaling in aging and Alzheimer's disease. Cold Spring Harb Perspect Biol. 2019;11. p. 1-14.

12. Yu X, Taylor AMW, Nagai J, Golshani P, Evans CJ, Coppola G, et al. Reducing astrocyte calcium signaling in vivo alters striatal microcircuits and causes repetitive behavior. Neuron. 2018;99:1170-87e9.

13. Nagai J, Rajbhandari AK, Gangwani MR, Hachisuka A, Coppola G, Masmanidis SC, et al. Hyperactivity with disrupted attention by activation of an astrocyte synaptogenic cue. Cell. 2019;177:1280-92e20.

14. Mu Y, Bennett DV, Rubinov M, Narayan S, Yang CT, Tanimoto $\mathrm{M}$, et al. Glia accumulate evidence that actions are futile and suppress unsuccessful behavior. Cell. 2019;178:27-43e19.

15. Liddelow SA, Sofroniew MV. Astrocytes usurp neurons as a disease focus. Nat Neurosci. 2019;22:512-3.

16. Iglesias T, Cabrera-Poch N, Mitchell MP, Naven TJ, Rozengurt E, Schiavo G. Identification and cloning of Kidins220, a novel neuronal substrate of protein kinase D. J Biol Chem. 2000;275:40048-56.

17. Kong H, Boulter J, Weber JL, Lai C, Chao MV. An evolutionarily conserved transmembrane protein that is a novel downstream target of neurotrophin and ephrin receptors. J Neurosci. 2001;21:176-85.

18. Arevalo JC, Yano H, Teng KK, Chao MV. A unique pathway for sustained neurotrophin signaling through an ankyrin-rich membrane-spanning protein. EMBO J. 2004;23:2358-68.

19. Luo S, Chen Y, Lai KO, Arevalo JC, Froehner SC, Adams ME, et al. \{alpha\}-Syntrophin regulates ARMS localization at the neuromuscular junction and enhances EphA4 signaling in an ARMS-dependent manner. J Cell Biol. 2005;169:813-24.

20. Lopez-Menendez C, Gascon S, Sobrado M, Vidaurre OG, Higuero AM, Rodriguez-Pena A, et al. Kidins220/ARMS downregulation by excitotoxic activation of NMDARs reveals its involvement in neuronal survival and death pathways. J Cell Sci. 2009;122:3554-65.

21. Arevalo JC, Wu SH, Takahashi T, Zhang H, Yu T, Yano H, et al. The ARMS/Kidins220 scaffold protein modulates synaptic transmission. Mol Cell Neurosci. 2010;45:92-100.

22. Cesca F, Yabe A, Spencer-Dene B, Scholz-Starke J, Medrihan L, Maden $\mathrm{CH}$, et al. Kidins220/ARMS mediates the integration of the neurotrophin and VEGF pathways in the vascular and nervous systems. Cell Death Differ. 2012;19:194-208.

23. Neubrand VE, Cesca F, Benfenati F, Schiavo G. Kidins220/ ARMS as a functional mediator of multiple receptor signalling pathways. J Cell Sci. 2012;125:1845-54.
24. Scholz-Starke J, Cesca F. Stepping out of the shade: control of neuronal activity by the scaffold protein Kidins220/ARMS. Front Cell Neurosci. 2016;10:68.

25. Cesca F, Yabe A, Spencer-Dene B, Arrigoni A, Al-Qatari M, Henderson D, et al. Kidins220/ARMS is an essential modulator of cardiovascular and nervous system development. Cell Death Dis. 2011;2:e226.

26. Wu SH, Arevalo JC, Sarti F, Tessarollo L, Gan WB, Chao MV. Ankyrin repeat-rich membrane Spanning/Kidins220 protein regulates dendritic branching and spine stability in vivo. Dev Neurobiol. 2009;69:547-57.

27. Wu SH, Arevalo JC, Neubrand VE, Zhang H, Arancio O, Chao MV. The ankyrin repeat-rich membrane spanning (ARMS)/ Kidins220 scaffold protein is regulated by activity-dependent calpain proteolysis and modulates synaptic plasticity. J Biol Chem. 2010;285:40472-8.

28. Duffy AM, Schaner MJ, Wu SH, Staniszewski A, Kumar A, Arevalo JC, et al. A selective role for ARMS/Kidins220 scaffold protein in spatial memory and trophic support of entorhinal and frontal cortical neurons. Exp Neurol. 2011;229:409-20.

29. Lopez-Benito S, Sanchez-Sanchez J, Brito V, Calvo L, Lisa S, Torres-Valle M, et al. Regulation of BDNF Release by ARMS/ Kidins220 through modulation of synaptotagmin-IV levels. J Neurosci. 2018;38:5415-28.

30. Scholz-Starke J, Cesca F, Schiavo G, Benfenati F, Baldelli P. Kidins220/ARMS is a novel modulator of short-term synaptic plasticity in hippocampal GABAergic neurons. PLoS One. 2012;7:e35785.

31. Kaeser PS, Deng L, Wang Y, Dulubova I, Liu X, Rizo J, et al. RIM proteins tether $\mathrm{Ca} 2+$ channels to presynaptic active zones via a direct PDZ-domain interaction. Cell. 2011;144:282-95.

32. Grynkiewicz G, Poenie M, Tsien RY. A new generation of $\mathrm{Ca} 2+$ indicators with greatly improved fluorescence properties. J Biol Chem. 1985;260:3440-50.

33. Vandesompele J, De Preter K, Pattyn F, Poppe B, Van Roy N, De Paepe A, et al. Accurate normalization of real-time quantitative RT-PCR data by geometric averaging of multiple internal control genes. Genome Biol. 2002;3:RESEARCH0034.

34. Parri HR, Gould TM, Crunelli V. Spontaneous astrocytic $\mathrm{Ca} 2+$ oscillations in situ drive NMDAR-mediated neuronal excitation. Nat Neurosci. 2001;4:803-12.

35. Kanemaru K, Okubo Y, Hirose K, Iino M. Regulation of neurite growth by spontaneous $\mathrm{Ca} 2+$ oscillations in astrocytes. J Neurosci. 2007;27:8957-66

36. Wang TF, Zhou C, Tang AH, Wang SQ, Chai Z. Cellular mechanism for spontaneous calcium oscillations in astrocytes. Acta Pharm Sin. 2006;27:861-8.

37. Yang YR, Follo MY, Cocco L, Suh PG. The physiological roles of primary phospholipase C. Adv Biol Regul. 2013;53:232-41.

38. Verkhratsky A, Parpura V. Store-operated calcium entry in neuroglia. Neurosci Bull. 2014;30:125-33.

39. Neary JT, van Breemen C, Forster E, Norenberg LO, Norenberg MD. ATP stimulates calcium influx in primary astrocyte cultures. Biochem Biophys Res Commun. 1988;157:1410-6.

40. Ben Achour S, Pont-Lezica L, Bechade C, Pascual O. Is astrocyte calcium signaling relevant for synaptic plasticity? Neuron Glia Biol. 2010;6:147-55.

41. Kwon J, An H, Sa M, Won J, Shin JI, Lee CJ. Orai1 and Orai3 in combination with Stim1 mediate the majority of store-operated calcium entry in astrocytes. Exp Neurobiol. 2017;26:42-54.

42. Sharp AH, Nucifora FC Jr. Blondel O, Sheppard CA, Zhang C, Snyder SH, et al. Differential cellular expression of isoforms of inositol 1,4,5-triphosphate receptors in neurons and glia in brain. $\mathrm{J}$ Comp Neurol. 1999;406:207-20. 
43. Holtzclaw LA, Pandhit S, Bare DJ, Mignery GA, Russell JT. Astrocytes in adult rat brain express type 2 inositol 1,4,5-trisphosphate receptors. Glia. 2002;39:69-84.

44. Yang J, Yang H, Liu Y, Li X, Qin L, Lou H, et al. Astrocytes contribute to synapse elimination via type 2 inositol 1,4,5-trisphosphate receptor-dependent release of ATP. Elife. 2016;5: e15043.

45. Verkhratsky A, Reyes RC, Parpura V. TRP channels coordinate ion signalling in astroglia. Rev Physiol Biochem Pharmacol. 2014;166:1-22.

46. Benfenati V, Amiry-Moghaddam M, Caprini M, Mylonakou MN, Rapisarda C, Ottersen OP, et al. Expression and functional characterization of transient receptor potential vanilloid-related channel 4 (TRPV4) in rat cortical astrocytes. Neuroscience. 2007;148: 876-92.

47. Butenko O, Dzamba D, Benesova J, Honsa P, Benfenati V, Rusnakova V, et al. The increased activity of TRPV4 channel in the astrocytes of the adult rat hippocampus after cerebral hypoxia/ ischemia. PLoS One. 2012;7:e39959.

48. Alberdi E, Sanchez-Gomez MV, Matute C. Calcium and glial cell death. Cell Calcium. 2005;38:417-25.

49. Deswal S, Meyer A, Fiala GJ, Eisenhardt AE, Schmitt LC, Salek M, et al. Kidins220/ARMS associates with B-Raf and the TCR, promoting sustained Erk signaling in T cells. J Immunol. 2013; 190:1927-35.

50. Fiala GJ, Janowska I, Prutek F, Hobeika E, Satapathy A, Sprenger A, et al. Kidins220/ARMS binds to the B cell antigen receptor and regulates B cell development and activation. J Exp Med. 2015;212:1693-708.

51. Kraft R. STIM and ORAI proteins in the nervous system. Channels. 2015;9:245-52.

52. Gao X, Xia J, Munoz FM, Manners MT, Pan R, Meucci O, et al. STIMs and Orail regulate cytokine production in spinal astrocytes. J Neuroinflammation. 2016;13:126.

53. Papanikolaou M, Lewis A, Butt AM. Store-operated calcium entry is essential for glial calcium signalling in CNS white matter. Brain Struct Funct. 2017;222:2993-3005.

54. Guler AD, Lee H, Iida T, Shimizu I, Tominaga M, Caterina M. Heat-evoked activation of the ion channel, TRPV4. J Neurosci. 2002;22:6408-14.

55. Liedtke W, Friedman JM. Abnormal osmotic regulation in trpv4-/mice. Proc Natl Acad Sci USA. 2003;100:13698-703.

56. Mizuno A, Matsumoto N, Imai M, Suzuki M. Impaired osmotic sensation in mice lacking TRPV4. Am J Physiol Cell Physiol. 2003;285:C96-101.
57. Dunn KM, Hill-Eubanks DC, Liedtke WB, Nelson MT. TRPV4 channels stimulate $\mathrm{Ca} 2+$-induced $\mathrm{Ca} 2+$ release in astrocytic endfeet and amplify neurovascular coupling responses. Proc Natl Acad Sci USA. 2013;110:6157-62.

58. Benfenati V, Caprini M, Dovizio M, Mylonakou MN, Ferroni S, Ottersen OP, et al. An aquaporin-4/transient receptor potential vanilloid 4 (AQP4/TRPV4) complex is essential for cell-volume control in astrocytes. Proc Natl Acad Sci USA. 2011;108:2563-8.

59. Dallerac G, Zapata J, Rouach N. Versatile control of synaptic circuits by astrocytes: where, when and how? Nat Rev Neurosci. 2018;19:729-43.

60. Liao YH, Hsu SM, Huang PH. ARMS depletion facilitates UV irradiation induced apoptotic cell death in melanoma. Cancer Res. 2007;67:11547-56.

61. Rogers DA, Schor NF. Kidins220/ARMS is expressed in neuroblastoma tumors and stabilizes neurotrophic signaling in a human neuroblastoma cell line. Pediatr Res. 2013;74:517-24.

62. Rogers DA, Schor NF. Kidins220/ARMS depletion is associated with the neural-to Schwann-like transition in a human neuroblastoma cell line model. Exp Cell Res. 2013;319:660-9.

63. Jung H, Shin JH, Park YS, Chang MS. Ankyrin repeat-rich membrane spanning (ARMS)/Kidins220 scaffold protein regulates neuroblastoma cell proliferation through p21. Molecules Cells. 2014;37:881-7.

64. Perea G, Araque A. Glial calcium signaling and neuron-glia communication. Cell Calcium. 2005;38:375-82.

65. Panatier A, Vallee J, Haber M, Murai KK, Lacaille JC, Robitaille R. Astrocytes are endogenous regulators of basal transmission at central synapses. Cell. 2011;146:785-98.

66. Cao X, Li LP, Wang Q, Wu Q, Hu HH, Zhang M, et al. Astrocytederived ATP modulates depressive-like behaviors. Nat Med. 2013;19:773-7.

67. Vardjan N, Kreft M, Zorec R. Regulated exocytosis in astrocytes is as slow as the metabolic availability of gliotransmitters: focus on glutamate and ATP. Adv Neurobiol. 2014;11:81-101.

68. Cotrina ML, Lin JH, Lopez-Garcia JC, Naus CC, Nedergaard M. ATP-mediated glia signaling. J Neurosci. 2000;20:2835-44.

69. Josifova DJ, Monroe GR, Tessadori F, de Graaff E, van der Zwaag B, Mehta SG, et al. Heterozygous KIDINS220/ARMS nonsense variants cause spastic paraplegia, intellectual disability, nystagmus, and obesity. Hum Mol Genet. 2016;25:2158-67.

70. Mero IL, Mork HH, Sheng Y, Blomhoff A, Opheim GL, Erichsen A, et al. Homozygous KIDINS220 loss-of-function variants in fetuses with cerebral ventriculomegaly and limb contractures. Hum Mol Genet. 2017;26:3792-6. 